\title{
PAISAJES RUPESTRES VINCULADOS A LA TRASHUMANCIA Y AL CARAVANEO DURANTE LOS DESARROLLOS REGIONALES (900-1430 DC) EN EL SUR DE POZUELOS (PUNA DE JUJUY, ARGENTINA)
}

\author{
ROCK-ART LANDSCAPES LINKED TO TRANSHUMANCE AND CARAVANS \\ DURING THE REGIONAL DEVELOPMENTS PERIOD (900-1430 AD) IN THE \\ SOUTH OF POZUELOS (PUNA OF JUJUY, ARGENTINA)
}

Silvina Rodríguez Curletto ${ }^{1,2,3}$, Mirella Sofía Lauricella ${ }^{4,2,3}$ y Carlos Angiorama ${ }^{4,2,3}$

\begin{abstract}
Este estudio aborda las implicancias de la articulación de diversos modos de movilidad y de prácticas pastoriles y caravaneras en los paisajes rupestres del sector sur de la cuenca de Pozuelos (Puna de Jujuy, Argentina), para momentos de los Desarrollos Regionales (900-1430 DC). Desde un enfoque teórico-metodológico que integra el estudio estilístico, contextual y la arqueología del paisaje, se propone para esta micro-región la existencia de circulación de personas, animales y conocimientos por medio de dos tipos de movilidad: la transhumancia pastoril y el tráfico caravanero. En un contexto de conflictividad interétnica propuesto por diversos autores para estos momentos, los paisajes rupestres analizados evidencian una performatividad iterativa que pudo ser mantenida y protegida por un grupo probablemente local, el cual perpetuó a través del tiempo una lógica y ritualidad recurrente, sostenida por un mismo conocimiento técnico, composicional y conceptual en la manufactura del arte rupestre. De este modo, se plantea la emergencia de lugares caravaneros y caravaneros/pastoriles en una de las rutas de ingreso/egreso sur-occidental de la cuenca de Pozuelos vinculada a estrategias de circulación micro-regional, que estaría interactuando de diferentes modos con las redes viales interregionales.
\end{abstract}

Palabras claves: paisajes rupestres, trashumancia, tráfico caravanero, Puna de Jujuy.

This study discusses the implications for rock-art landscapes of the articulation between different modes of mobility and pastoral and caravan practices in the southern Pozuelos basin (Puna of Jujuy, Argentina) during the Regional Developments Period (900-1430 AD). From a theoretical-methodological approach that integrates the stylistic and contextual study as well as the archeology of landscape, it is proposed that people, animals and knowledge circulated in this micro-region via two types of mobility: pastoral transhumance and caravan traffic. In a context of interethnic conflict as suggested by several authors for this period, the analyzed rock-art landscapes show an iterative performativity that could be maintained and protected by a group that was probably local, which perpetuated through time a recurring logic and rituality, sustained by the same technical, compositional and conceptual knowledge found in the manufacture of rock art. Thus, this study proposes the existence of caravan and caravan/pastoralist locations along one of the southwestern routes entering and leaving the Pozuelos basin associated with a micro-regional mode of circulation that interacted in different ways with the interregional traffic networks.

Key words: Rock-art landscapes, transhumance, caravan traffic, Puna of Jujuy.

Las investigaciones realizadas en torno a comunidades agro-pastoriles en los Andes centromeridionales, han permitido conocer diferentes aspectos de la logística y la ritualidad inherentes tanto a las prácticas pastoriles como a las caravaneras, dos actividades de enorme relevancia en la Puna de Jujuy, una porción del altiplano surandino localizada en el actual Noroeste Argentino. En estas comunidades, las redes de intercambio jugaron un rol decisivo en los modos de interacción cultural y en la circulación de personas, de bienes materiales y de conocimientos, como así también en el desarrollo de las identidades locales, las fronteras (físicas y virtuales), y las negociaciones políticas.

El arte rupestre vinculado a las prácticas de caravaneo en esta región, incluye la presencia de manifestaciones rupestres de recuas de llamas con o sin agente guía, que se emplazan de diferentes modos en

\footnotetext{
${ }^{1}$ Instituto de Ciencias de la Tierra, Biodiversidad y Sustentabilidad Ambiental (ICBIA), Facultad de Ciencias Exactas Físico-Químicas y Naturales, Universidad Nacional de Río Cuarto, Río Cuarto, Argentina. silvina.curletto@gmail.com ${ }^{2}$ Consejo Nacional de Investigaciones Científicas y Técnicas (CONICET), Buenos Aires, Argentina.

${ }^{3}$ Instituto de Arqueología y Museo, Universidad Nacional de Tucumán, Tucumán, Argentina.

${ }^{4}$ Instituto Superior de Estudios Sociales (ISES), Tucumán, Argentina. mirellasofia@yahoo.com.ar; carlosangiorama@gmail.com
} 
las rutas prehispánicas de tráfico de bienes. De alguna manera, estos paisajes rupestres parecen implicar una ritualidad en la práctica de intercambio de bienes que se repite en diferentes rutas de corta y larga distancia, aunque con ciertas particularidades que no solo han cambiado a través del tiempo, sino también en relación a sus objetivos y a las escalas de dichas interconexiones (regionales o interregionales) (Aschero 2000; Berenguer 2004; Nielsen 1997/1998, 2006).

Vinculadas al caravaneo, se encuentran las prácticas pastoriles que presentan un carácter extensivo, con un uso vertical de los espacios por medio de una movilidad transhumante que articula, para una misma familia, diferentes tipos de asentamientos (bases residenciales, puestos temporarios, estaciones), garantizando de este modo el mantenimiento de los rebaños (alimentación, cuidado, rituales, reproducción). El arte rupestre relacionado con estos paisajes pastoriles presenta, en general, camélidos agrupados, en rebaños, con crías, en corrales y vinculados también a diversos patrones de la figura humana (Aschero 1998 [1996], 2000; Martel 2010).

En este contexto, el objetivo principal de este artículo consiste en comprender las implicancias de la articulación de diversos tipos de movilidad y de prácticas pastoriles y caravaneras ${ }^{1}$, en los paisajes rupestres del sector sur de la cuenca de Pozuelos (Puna de Jujuy, Argentina).

Considerando la configuración de las dos modalidades estilísticas definidas en el área de estudio para el período de los Desarrollos Regionales (900-1430 DC), a saber, la Modalidad Estilística Ciénega Rodeo (MECiR en adelante) y la Modalidad Estilística Río Herrana (MERH en adelante) (Lauricella 2016; Rodríguez Curletto 2014;
Rodríguez Curletto y Angiorama 2016), analizamos en detalle dos paisajes rupestres, Abra Pintada 1 y Río Candado 2, y los vinculamos con investigaciones previas realizadas en los sitios Tabladitas 1 y Pukara de Rinconada (Alfaro de Lanzone 1969; Boman 1908; Rodríguez Curletto 2014; Ruiz y Chorolque 2007). El abordaje teórico-metodológico propuesto se sustenta en la arqueología del paisaje, el análisis estilístico y el estudio contextual (Aschero 2000,2006; Harris 1991; Ingold 2000), teniendo como ejes principales la sinergética, las relaciones de saber-poder y la iteratividad y performatividad de las prácticas que producen la emergencia de sujetos/agentes y lugares (sensu Barad 2008c; Foucault 1979; Haken 1988). A partir de lo mencionado, este trabajo pretende que los resultados obtenidos sirvan de base para integrar, según esta perspectiva teórico-metodológica, el resto de los paisajes rupestres del sur Pozuelos.

\section{Contexto Geográfico-Ambiental y Arte Rupestre de Pozuelos}

La cuenca de Pozuelos se localiza en el extremo meridional del altiplano surandino, abarcando territorio tanto de Argentina como de Bolivia. Se trata de una de las principales cuencas endorreicas de la región puneña, ubicada por encima de los $3.600 \mathrm{msm}$. Se encuentra delimitada por las Sierras de Santa Catalina, Rinconada y Carahuasi al oeste, la Sierra de Quichagua al sur, y las Sierras de Escaya y Cochinoca al este.

En el presente trabajo hacemos foco en el sector sur de la cuenca, ubicado en parte de los departamentos de Rinconada y Cochinoca de la provincia de Jujuy, Argentina (Figura 1). Este territorio se encuentra conformado por

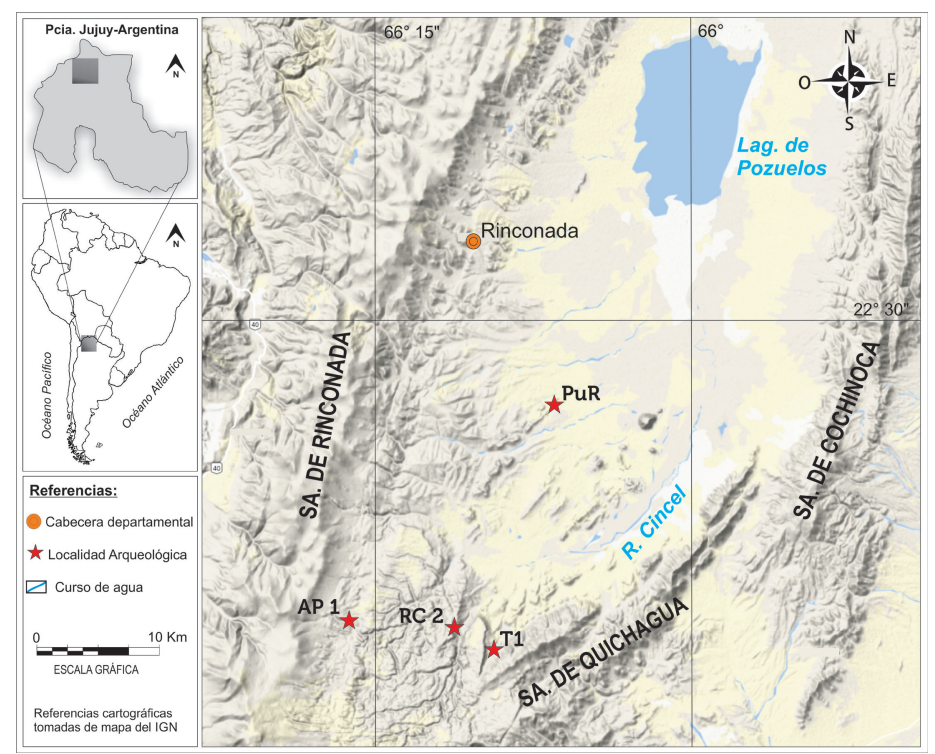

Figura 1. Mapa de ubicación de los sitios arqueológicos Abra Pintada 1 (AP1), Río Candado 2 (RC2), Tabladitas 1 (T1) y Pukara de Rinconada (PuR).

Location map of the archaeological sites Abra Pintada 1 (AP1), Río Candado 2 (RC2), Tabladitas 1 (T1) and Pukara de Rinconada (PuR). 
zonas con planicies de sedimentos cuaternarios, las cuales se interrumpen por formaciones montañosas de rocas sedimentarias de diversos colores y por altas terrazas de rocas volcánicas, entre las que fluyen los principales cursos de agua de la microrregión como los ríos Candado, Herrana, San José y Cincel (Coira et al. 2004).

A principios del siglo XX, Eric Boman (1908) menciona la presencia de arte rupestre en las paredes de ignimbrita del Pukara de Rinconada, posteriormente se realizan nuevas investigaciones arqueológicas que permiten una primera caracterización de estas manifestaciones rupestres en los alrededores inmediatos del sitio (Alfaro de Lanzone 1969; Ruiz 2002; Ruiz y Chorolque 2007). En el año 2004, nuestro equipo de investigación inició trabajos de campo intensivos en el sur de la Cuenca de Pozuelos que permitieron identificar y analizar sitios con arte rupestre con una amplia variabilidad de emplazamientos, estilos, contextos asociados, y con una profundidad temporal que alcanza el Arcaico y llega hasta momentos de la Colonia (Angiorama y Del Bel 2012; Lauricella 2016; Rodríguez Curletto 2014; Rodríguez Curletto y Angiorama 2016; entre otros).

Particularmente para el período de los Desarrollos Regionales en el sur de la Cuenca de Pozuelos, hemos definido dos Modalidades Estilísticas (sensu Aschero 2006) que se encuentran interactuando de diferentes modos. Siguiendo a Aschero (1979), estas manifestaciones rupestres han sido ubicadas dentro del Grupo Estilístico C, Subgrupo Estilístico C1; y para nuestra microrregión en particular, han sido denominadas Modalidad Estilística Ciénega Rodeo (MECiR) y Modalidad Estilística Río Herrana (MERH) (Rodríguez Curletto 2014; Rodríguez Curletto y Angiorama 2016).

La MECiR presenta manifestaciones rupestres muy estandarizadas ejecutadas mediante las técnicas de pintura, grabado, y pictograbado. Los colores utilizados en las pinturas son el negro, rojo, amarillo y blanco; mientras que los grabados están ejecutados mediante picado (muy regular) en surco, plano y en punto, cuentan con bordes muy definidos y el interior con diferentes grados de abrasión (regular y alisado). Los principales elementos identificados son los antropomorfos con los patrones G3 (contorno subtriangular o de trapecio isósceles), H2 (de lados rectos y de lados cóncavos), H3-H4 (escutiformes), H5 (antropomorfos “T”) (Aschero 2000) y la figura del escutiforme de perfil (Podestá et al. 2013). En la mayoría de los casos, cuentan con adornos cefálicos complejos, algunos con diseños internos en la vestimenta, portando objetos, armas; y se disponen en filas, en columnas, enfrentados y aislados en posición destacada. LaMECiR se caracteriza por una gran cantidad de camélidos (varios con jabot y enflorados), dispuestos de perfil, formando motivos de caravanas (algunas con carga), en rebaño, con cría, enfrentados y aislados.
La MERH cuenta con manifestaciones rupestres muy diversas ejecutadas mediante la técnica de grabado: por picado en surco sin abrasión interna en general, o directamente por abrasión muy irregular y raspado sobre la superficie rocosa, y solo algunos casos excepcionales de pintura roja. Los principales elementos identificados son los cuadrúpedos, posibles taruca, cánido y camélidos, siendo estos últimos los más frecuentes ya sea con cría, aislados, en corrales, o en fila (algunas posibles caravanas), mientras que en el caso de los antropomorfos que son más escasos, se identifican solo los patrones $\mathrm{H} 1$ y $\mathrm{H} 2$ (de lados rectos), la mayoría aislados (algunos portando objetos) o asociados a cuadrúpedos.

Las propiedades de los paisajes en ambas modalidades estilísticas son similares con una visualización media a alta en todos los casos, aunque en general la MECiR presenta una visibilización mayor que la MERH. Esto quiere decir que mientras ambas manejan un campo visual similar hacia el entorno, la MECiR presenta mayor capacidad de ser observada desde dicho entorno (Rodríguez Curletto 2014; Rodríguez Curletto y Angiorama 2016).

\section{Reflexiones Teóricas}

Como punto de partida, destacamos nuestra distancia con la perspectiva representacional ya que no consideramos que las manifestaciones rupestres estén en lugar de algo más representando una realidad que es observada pasivamente (Olsen 2012), sino que el mismo acto de pintar y grabar sobre la roca constituye la realidad en sí misma, una realidad que transmuta constantemente el mundo, tanto para quien lo ejecuta como para quien lo observa. Por este motivo, nos referimos a ellas como manifestaciones rupestres en lugar de representaciones rupestres, ya que consideramos que tanto su ejecución como su observación no es pasiva ni inocente, sino que el poder generativo de dichas prácticas es performativo en sí mismo (Butler 2002, 2007).

Esta manera de concebir las prácticas, nos invita a superar el estatismo con el que solemos ver al arte rupestre y nos permite pensar en la emergencia de sujetos y lugares que serían performados constantemente por una intra-acción iterativa (sensu Barad 2008) entre los diferentes agentes y las materialidades involucradas. Consideramos que la iteratividad de estas performatividades se produce desde la interpelación y el conflicto que genera el encuentro de identidades individuales y colectivas, a través tanto de los paisajes rupestres como de las prácticas pastoriles y prácticas caravaneras involucradas en dichas emergencias.

Para este enfoque proponemos abordar la complejidad (sensu Gellmann 1995) de las manifestaciones rupestres, integrando conceptos de la sinergética (sensu Haken 1988), la performatividad de 
las prácticas y sus implicancias en la emergencia de sujetos/agentes (Butler 2002, 2007; Foucault 1979) y de lugares (Ingold 2000).

La sinergética (sensu Haken 1988) que estudia procesos estocásticos, permite el abordaje de cambios cualitativos en sistemas complejos, y en especial las relaciones de sus partes constituyentes que pueden ser las generadoras de propiedades emergentes. De este modo, la conformación de los paisajes rupestres, se daría en varios planos diferentes interconectados, donde la presencia de ciertos caracteres podría evocar diferentes normas que pueden coexistir y retroalimentarse dinámicamente. La sinergia y la intra-acción iterativa de las partes constitutivas de estos sistemas complejos (prácticas, conocimientos, técnicas de ejecución de las manifestaciones rupestres, paisajes, personas, animales, etc.) podrían observarse en la emergencia del sujeto/ agente y del lugar, que supera la sumatoria de las partes que los constituyen.

Las relaciones de poder tienen un rol fundamental en la emergencia y performatividad del sujeto/ agente y del lugar. Si bien el poder crea y subordina al sujeto, es al mismo tiempo su condición de reflexividad, por tanto los efectos del poder que son dinámicos y generativos forman un sujeto/agente que no es pasivo y que puede subvertir y transformar el poder y las normas que lo originaron justamente a través de su propia agencia (sensu Butler 2002, 2007). Por este motivo, no pensamos en una estructura de poder piramidal en términos de modelo de jefatura (Tarragó 2000), sino en la visualización de formas heterogéneas de saber-poder, disperso de manera reticular en un colectivo social (sensu Foucault 1979, 2015).

Esto implica, que la sinergia de los paisajes rupestres permitirían al ejecutor/observador la aprehensión de su propia identidad en lo que podríamos pensar como un rito performativo articulado por un conjunto de normas (pero no completamente definido por ellas) (Butler 2007), que estarían presentes en la configuración de las manifestaciones rupestres, en la cadena operativa de su ejecución, en los modos de pintar o grabar, en las prácticas rituales asociadas, en la selección de un determinado paisaje, etc.

Teniendo en cuenta estos aspectos, el abordaje teórico-metodológico propuesto (Rodríguez Curletto y Angiorama 2016) gira en torno al análisis estilístico (Aschero 1979, 2000, 2006), el estudio contextual de las manifestaciones rupestres (Aschero 2000, 2006) y la arqueología del paisaje (Criado Boado 1999; Ingold 2000; Tilley 2004).

\section{Metodología}

La metodología implementada buscó abordar los tres ejes principales mencionados en el apartado anterior (paisajes, estilos y contextos), tanto en la etapa de campo como de gabinete. De este modo, para la documentación de los sitios se realizaron relevamientos de campo mediante croquis, fichas de registro ad hoc, calcos in situ en plásticos de polietileno y fotografías digitales. Toda esta información fue posteriormente analizada en gabinete, mediante la utilización de softwares específicos ${ }^{2}$ que nos permitieron el procesamiento de toda la información.

Para el estudio estilístico de las manifestaciones rupestres (Aschero 1979, 2000, 2006) se llevó a cabo un análisis que involucra: (1) definición de las figuras/ elementos (camélido, antropomorfo), los cuales componen un motivo (caravana con antropomorfo guía), y estos últimos conforman diferentes temas (caravanero); (2) caracterización de los elementos mediante su geometría, descripción de atributos, morfología, disposición, orientación, angularidad, rasgos de acción/expresión, entre otros, lo que nos permitió vincular los diferentes elementos a los cánones y patrones definidos para el Noroeste Argentino (Aschero 2000; Podestá et al. 2013); (3) identificación de las técnicas de ejecución (pintura, grabado y pictograbado), junto a las diferencias de pátinas en los grabados y diferencias cromáticas en las pinturas, que permitió definir Conjuntos Técnicos $(\mathrm{CTe})$ y TécnicoCromáticos $^{3}(\mathrm{CTe}-\mathrm{Cr})$. La aplicación de pintura puede ser mediante el trazo lineal (L), plano (Pl) y puntiforme $(\mathrm{Pu})$; mientras que los grabados pueden ser ejecutados mediante el picado y la abrasión, en varias oportunidades combinando ambas técnicas. El picado puede ser en surco (Ps.), plano (Ppl.) y en punto (Ppu.), mientras que la abrasión puede ser regular (Reg.), irregular (Irr.), alisado (Alis.) y raspado (Rasp.). Los grabados presentan además variabilidad en sus perfiles (sección transversal del grabado), el perfil en "L" (picado plano con bordes rectos y el interior plano muy regular), en "U", en "V" abierta y "V" cerrada (incisión) (Figura 2a); (4) clasificación de las relaciones establecidas entre los elementos en la conformación de los motivos como así también de su distribución dentro del espacio plástico de cada Unidad Topográfica ${ }^{4}$ (UT en adelante); (5) análisis de las superposiciones, yuxtaposiciones, reutilizaciones y reciclados entre elementos para establecer, junto a todos los aspectos mencionados anteriormente, los diferentes eventos de ejecución presentes en cada UT; y finalmente, (6) articulación de todos los atributos y relaciones en una matrix (sensu lato Harris 1991) que integra las relaciones técnicas de cada UT, para luego ser extrapolada a nivel global con el resto de las UT del sitio, y de este modo, definir los tipos de vínculos técnico-estilísticos identificados entre los CTe y CTe$\mathrm{Cr}$, los cuales se exponen gráficamente en un diagrama (Figura 2b), en el que cada uno de los círculos o elipses concéntricas que lo constituyen implica la existencia de dichos vínculos. 


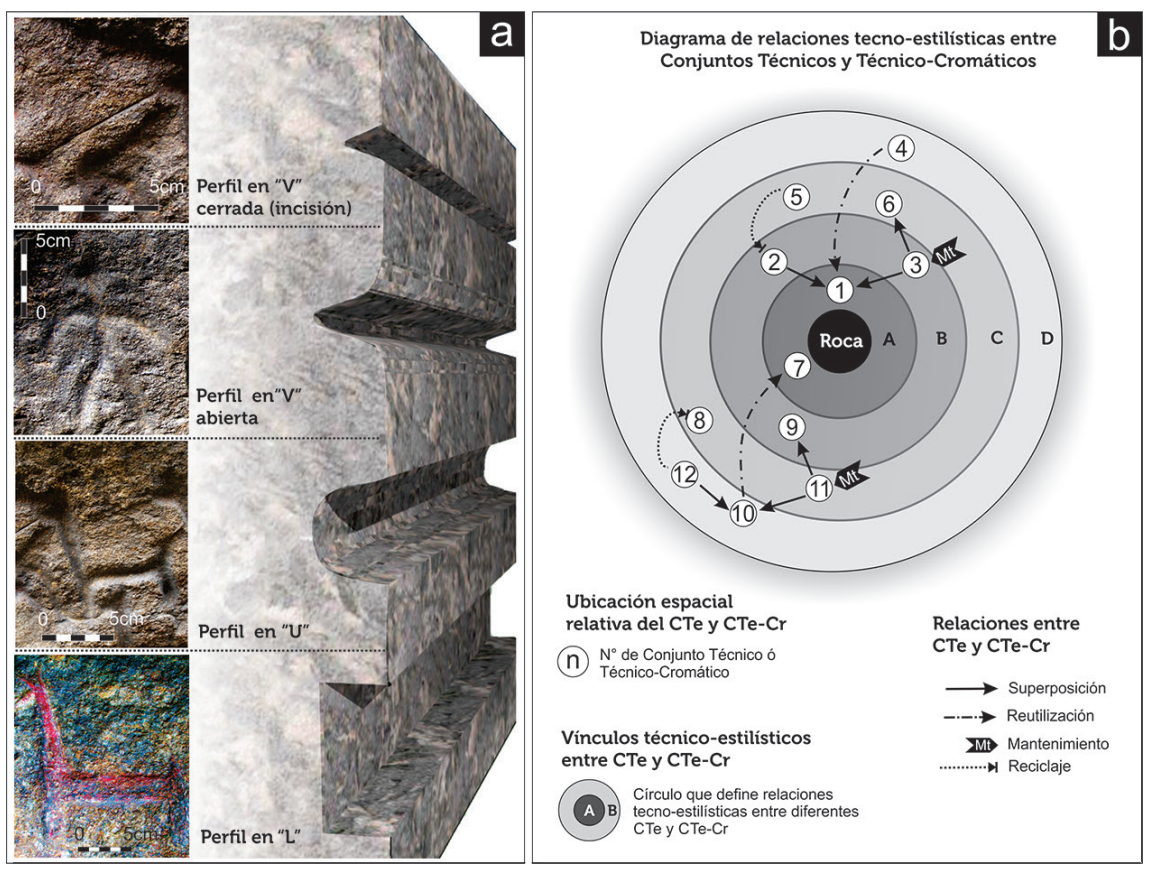

Figura 2. (a) Gráfico de corte transversal virtual de los diferentes tipos de grabados registrados en el sur de Pozuelos. (b) Diagrama hipotético de relaciones técnico-estilísticas a modo explicativo.

(a) Virtual cross-section graph of the different types of engravings recorded in the south of Pozuelos. (b) Hypothetical diagram of technical-stylistic relations by way of explanation.

Para el estudio del contexto y del paisaje, se realiza: (1) análisis del emplazamiento y ubicación del sitio en relación a la geografía, geología, geomorfología, fitogeografía e hidrología local; (2) análisis de la asociación espacial con sitios arqueológicos aledaños y con restos materiales culturales muebles e inmuebles; (3) análisis de sendas de tránsito y (4) análisis de las condiciones de accesibilidad física y de visualización del arte rupestre, que comprende tanto el estudio de la visibilización o forma cómo un elemento arqueológico es visto, de la visibilidad o panorámica que se domina desde él como el de la intervisibilidad o relación visual entre ese elemento y otros, sean o no arqueológicos (sensu Criado Boado 1999). La evaluación de estos aspectos permite definir por ejemplo, la existencia de puntos de inflexión (articulación de fisiografías contrastantes y su relación a sendas de tránsito), como así también de paisajes coyunturales, los cuales además de constituir un punto de inflexión, también cuentan con la confluencia de propiedades particulares en el arte rupestre como la articulación de modalidades estilísticas y de repertorios temáticos distintos en un mismo paisaje.

\section{Materiales}

En este estudio analizamos dos sitios arqueológicos con manifestaciones rupestres del sur de Pozuelos, Abra Pintada 1 y Río Candado 2, mediante la metodología aquí presentada. Asimismo, con el fin de extrapolar ciertos aspectos puntuales vinculados a los sitios mencionados, se consideran también los sitios Tabladitas 1 y el Pukara de Rinconada a partir de investigaciones previas (Alfaro de Lanzone 1969; Boman 1908; Rodríguez Curletto 2014; Ruiz y Chorolque 2007).

Abra Pintada 1 (AP1 en adelante) y Río Candado 2 (RC2 en adelante) comprenden un total de 13 Unidades Topográficas, compuestas por 451 elementos adscribibles a momentos de los Desarrollos Regionales (900-1430 DC) (Tabla 1), sin presencia hasta el momento, de arte rupestre vinculable a otros periodos. Las técnicas de ejecución identificadas en ambos sitios corresponden a la pintura de color rojo con diferencias en la intensidad y el valor, mientras que en RC2 además, se registran elementos grabados y pictograbados (Tabla 2). 
Tabla 1. Caracterización de elementos de Abra Pintada 1 y Río Candado 2.

Elements characterization of Abra Pintada 1 and Río Candado 2.

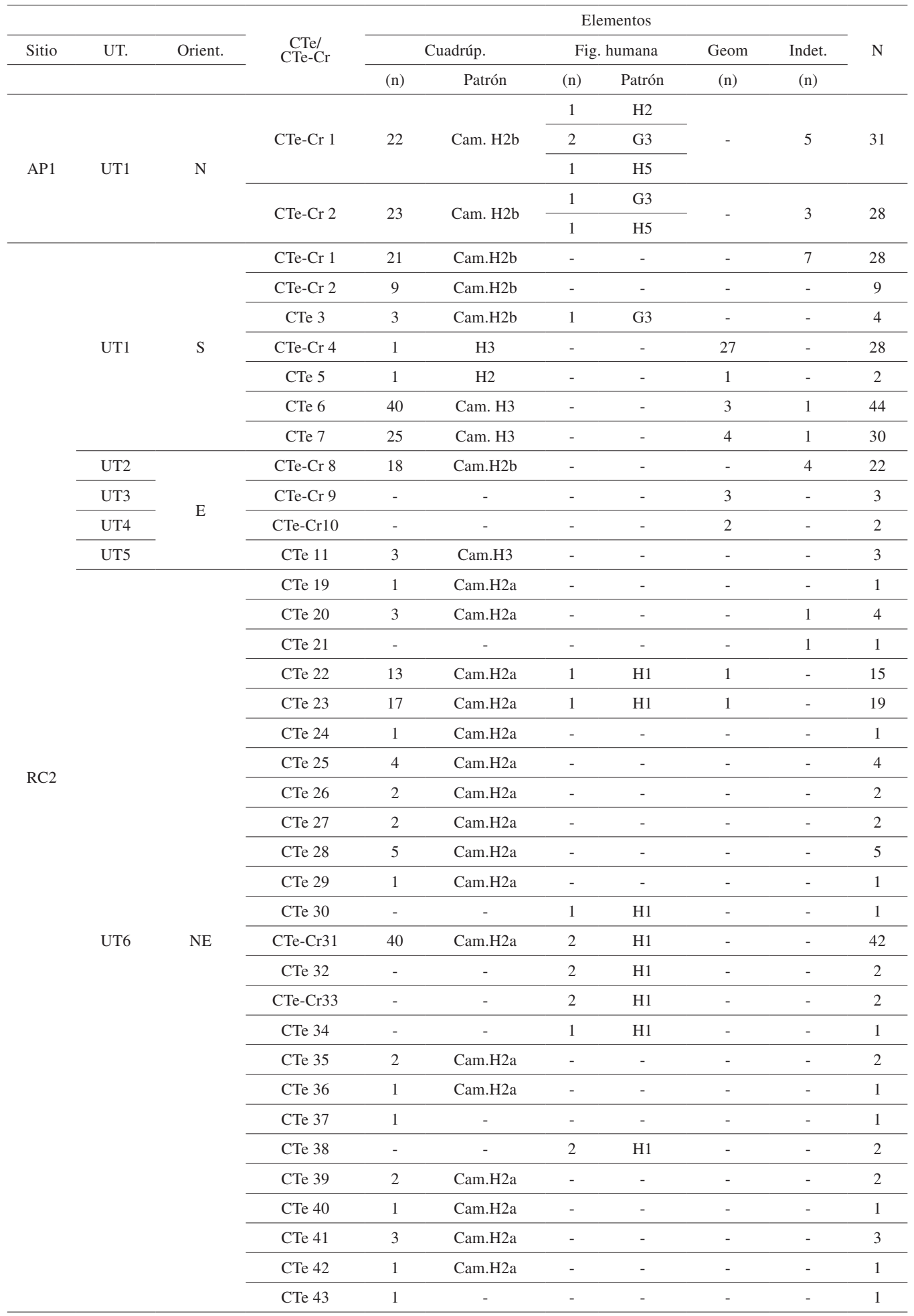


Continuación Tabla 1.

\begin{tabular}{|c|c|c|c|c|c|c|c|c|c|c|}
\hline \multirow{3}{*}{ Sitio } & \multirow{3}{*}{ UT. } & \multirow{3}{*}{ Orient. } & \multirow{3}{*}{$\begin{array}{c}\mathrm{CTe} / \\
\text { CTe-Cr }\end{array}$} & \multicolumn{6}{|c|}{ Elementos } & \multirow{3}{*}{$\mathrm{N}$} \\
\hline & & & & \multicolumn{2}{|c|}{ Cuadrúp. } & \multicolumn{2}{|c|}{ Fig. humana } & \multirow{2}{*}{$\begin{array}{c}\text { Geom } \\
\text { (n) }\end{array}$} & \multirow{2}{*}{$\begin{array}{c}\text { Indet. } \\
\text { (n) }\end{array}$} & \\
\hline & & & & (n) & Patrón & (n) & Patrón & & & \\
\hline \multirow{20}{*}{$\mathrm{RC} 2$} & \multirow{8}{*}{ UT6 } & \multirow{17}{*}{ NE } & CTe 44 & 2 & Cam.H2a & - & - & - & - & 2 \\
\hline & & & $\mathrm{CTe} 45$ & 1 & Cam.H2a & - & - & - & - & 1 \\
\hline & & & CTe 46 & 9 & Cam.H2a & - & - & - & - & 9 \\
\hline & & & CTe 47 & 17 & Cam.H2a & - & - & - & - & 17 \\
\hline & & & $\mathrm{CTe}-\mathrm{Cr} 48$ & 13 & Cam.H2a & - & - & - & - & 13 \\
\hline & & & CTe 49 & 3 & Cam.H2a & - & - & - & - & 3 \\
\hline & & & $\mathrm{CTe}-\mathrm{Cr} 50$ & 3 & Cam.H2a & - & - & - & - & 3 \\
\hline & & & CTe 51 & - & - & - & - & 4 & - & 4 \\
\hline & \multirow{2}{*}{ UT7 } & & CTe-Cr14 & 4 & Cam.H2a & - & - & - & - & 4 \\
\hline & & & \multirow{3}{*}{ CTe-Cr13 } & 4 & \multirow{3}{*}{ Cam. H2b } & 1 & G3/H5 & 4 & - & 9 \\
\hline & UT8 & & & 1 & & - & - & - & - & 1 \\
\hline & \multirow{5}{*}{ UT9 } & & & 2 & & - & - & - & - & 2 \\
\hline & & & CTe 15 & 2 & Cam.H2a & - & - & - & - & 2 \\
\hline & & & CTe-Cr16 & 3 & Cam.H2b & - & - & - & 5 & 8 \\
\hline & & & CTe 17 & 1 & Cam. H2a & - & - & - & - & 1 \\
\hline & & & CТe 18 & 1 & - & - & - & - & - & 1 \\
\hline & UT10 & & $\mathrm{CTe}-\mathrm{Cr} 12$ & 5 & Cam.H2a & - & - & 1 & - & 6 \\
\hline & \multirow{2}{*}{ UT11 } & \multirow{2}{*}{$\mathrm{N}$} & CTe-Cr52 & 4 & Cam.H2 & - & - & 1 & 3 & 8 \\
\hline & & & $\mathrm{CTe}-\mathrm{Cr} 53$ & 4 & Cam.H3 & - & - & - & 1 & 5 \\
\hline & UT12 & $\mathrm{O}$ & CTe54 & 1 & Cam.H3 & - & - & - & - & 1 \\
\hline \multicolumn{2}{|c|}{ Totales } & & & 347 & & 20 & & 52 & 32 & 451 \\
\hline
\end{tabular}

Las manifestaciones rupestres consideradas a partir de trabajos previos en Tabladitas 1 ( $\mathrm{T} 1$ en adelante) presentan elementos pintados en color rojo, mientras que los del Pukara de Rinconada (PuR en adelante) presentan diversidad de colores en las pinturas (rojo, negro y blanco), al mismo tiempo que contienen grabados y pictograbados.

\section{Resultados}

\section{Abra Pintada 1 (AP1)}

\section{Paisaje y manifestaciones rupestres}

El sitio AP1 se ubica al suroeste de nuestra área de estudio, en una subcuenca de altura en la Sierra de Carahuasi. Se emplaza en un área de contacto entre dos ambientes geológicos, justamente en el límite occidental de las mesetas ignimbríticas de la formación Coranzulí, y el borde oriental de las rocas sedimentarias del basamento Ordovícico (Prezzi y Lince Klinger 2010, Coira et al. 2004). A una altura de $4.040 \mathrm{msm}$, AP1 se sitúa en la ladera media-baja del afloramiento de ignimbrita, prácticamente en el borde de contacto con la llanura aluvial de un curso de agua que discurre por la base de estos afloramientos, con sentido oeste-este y que desemboca hacia el noreste, en la cuenca del Río Cincel (Figura 3a y c).

Las manifestaciones rupestres se ubican en un bloque de ignimbrita de gran tamaño $(3,50 \mathrm{~m} \times 3$ $\mathrm{m})$, desprendido de la zona cumbral del afloramiento rocoso. El bloque presenta una superficie vertical plana con orientación norte-noroeste, sobre la que se encuentra la UT1 con arte rupestre. En su extremo oriental y coincidente con la base, se presenta una acumulación antrópica de rocas de formas prismáticas y redondeadas. Del lado norte y adyacente al soporte, se observa una senda de tránsito que presenta dirección este-oeste, la cual conecta la mencionada llanura aluvial con la cima del afloramiento. Allí se ubica un ciénego con dos refugios circulares asociados a un corral, todos de gran antigüedad, y donde se emplaza un puesto pastoril actualmente habitado durante parte del año (Figura 3b).

La UT1 es perfectamente visible desde la senda adyacente que pasa por el lado norte del bloque rocoso, sin embargo su visibilización es baja más allá de dicha senda. Cuenta con una alta visibilidad hacia la llanura aluvial y baja hacia la cima del afloramiento rocoso, mientras que no cuenta con intervisibilidad con otros sitios cercanos. 


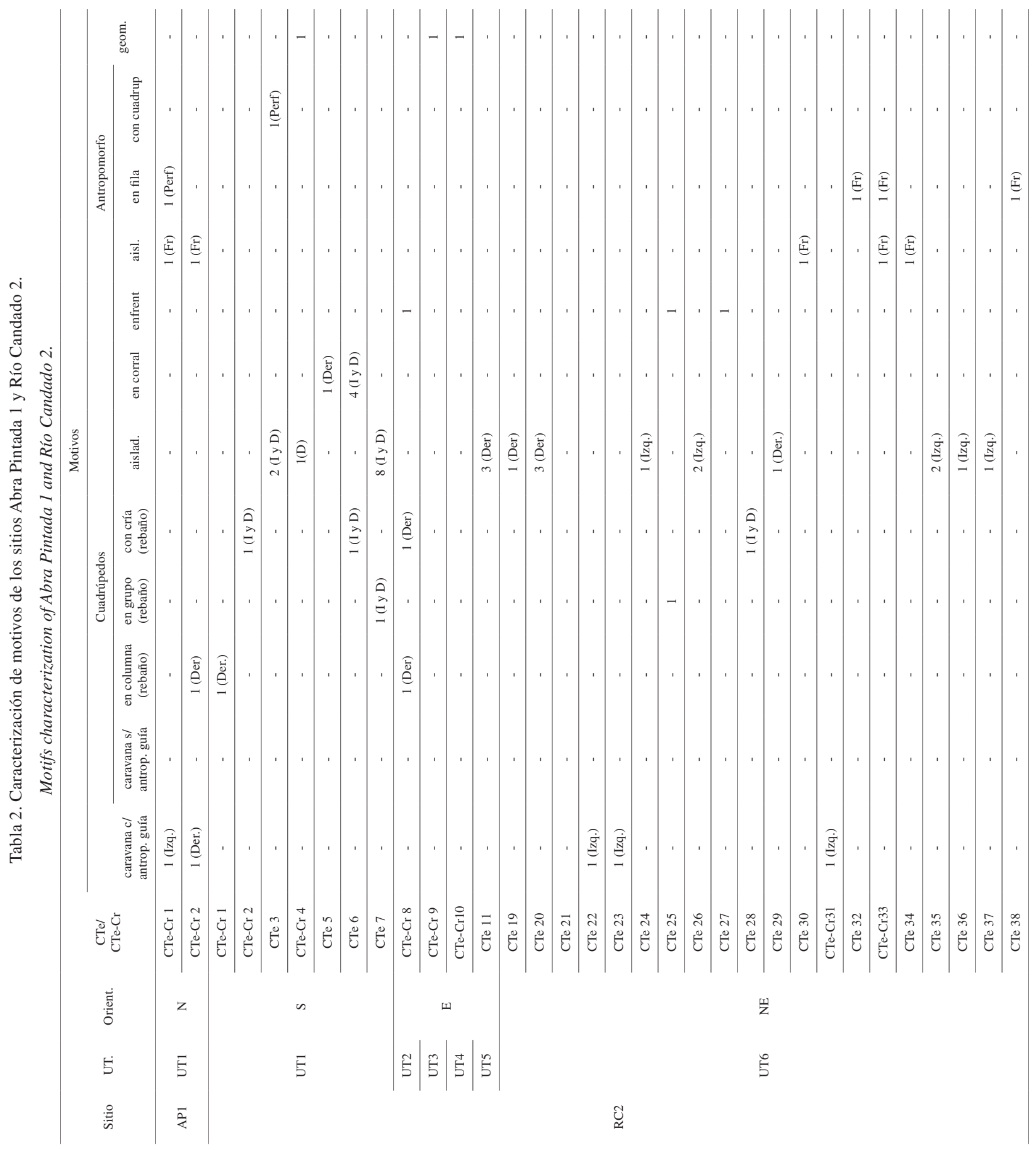




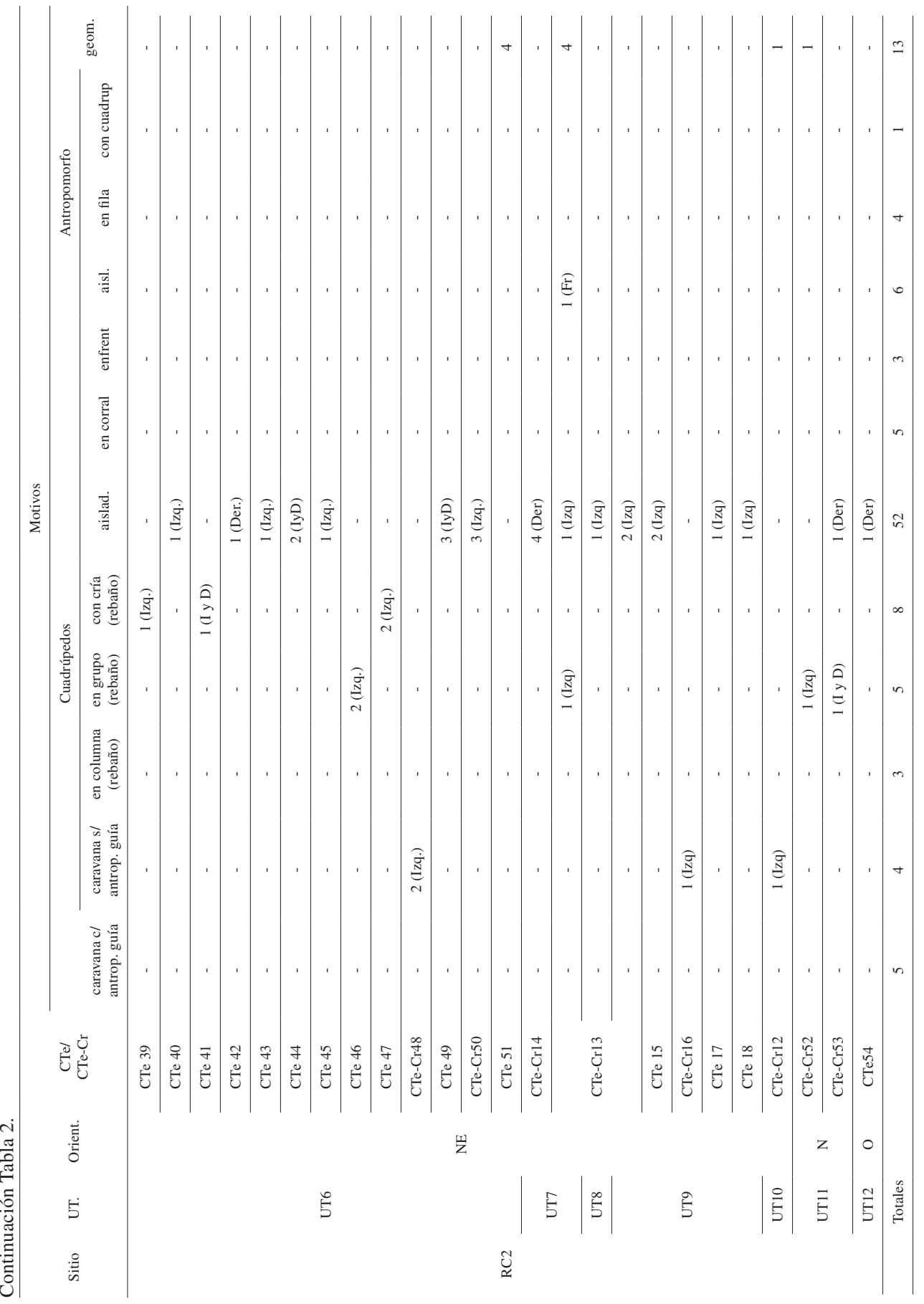




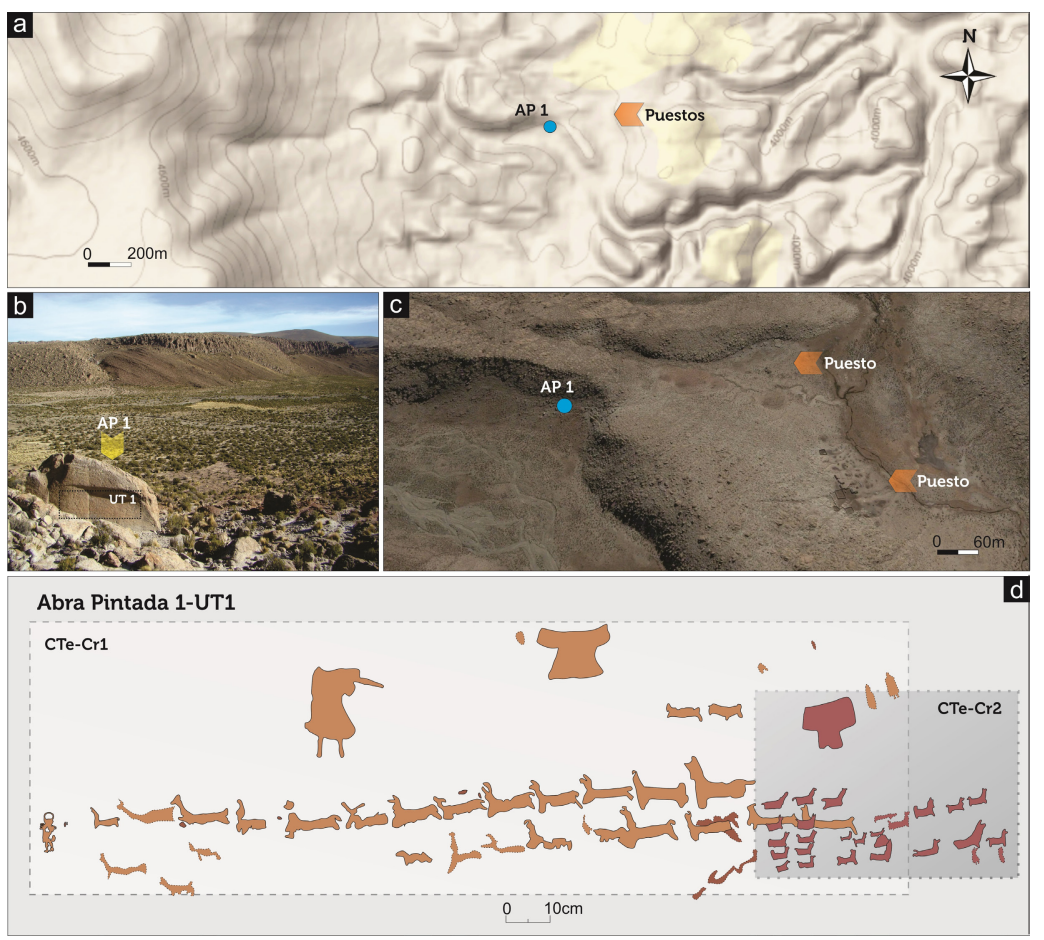

Figura 3. (a) Ubicación de AP1. (b) Paisaje de AP1 y ubicación de la UT1. (c) Emplazamiento de AP1 y puestos actuales cercanos. (d) Manifestaciones rupestres de AP1 (CTe-Cr1 y CTe-Cr2).

(a) Location of AP1. (b) Landscape of AP1 and location of TU1. (c) Location of AP1 and current temporary settlements. (d) Rock manifestations of AP1 (CTe-Crl and CTe-Cr2).

Las manifestaciones rupestres de esta UT1 están ejecutadas mediante la técnica de pintura (trazo lineal y plano), de color rojo-anaranjado y rojovioláceo (Tabla 3). Los análisis técnico-estilísticos nos permitieron identificar dos conjuntos (CTe-Cr1 y CTe$\mathrm{Cr} 2$ ) ambos vinculados al tema de caravaneo (Figura 3d). Los elementos identificados en ambos conjuntos corresponden a camélidos del patrón $\mathrm{H} 2 \mathrm{~b}$ y a la figura humana de los patrones H2, G3 y H5 (Aschero 2000) en variadas disposiciones y escalas (sensu Alberti 2013), que conforman motivos de caravanas con antropomorfo guía, antropomorfos en fila y aislados, y camélidos sin extremidades dispuestos en columnas, como si se tratara de un rebaño en actitud o situación de descanso (Rodríguez Curletto 2014).

Ambos Conjuntos Técnico-Cromáticos pueden ser vinculados a la MECiR. Asimismo, las pequeñas diferencias técnicas, proporcionales y composicionales observadas en la configuración de figuras similares entre los Conjuntos $\mathrm{Te}-\mathrm{Cr}$, junto a la diferencia de tonalidades de rojo y las superposiciones identificadas, nos permiten reconocer al menos dos eventos de ejecución: un primer momento para el CTe-Cr1, y otro posterior para el CTe-Cr2 (Figura 3d).

\section{Río Candado 2}

\section{Paisaje y manifestaciones rupestres}

El sitio RC2 se localiza al suroeste de la cuenca de Pozuelos, en la parte baja de una subcuenca en la que discurre el río homónimo con sentido sur-norte, y que desemboca hacia el noreste en la cuenca del Río Cincel. Se ubica en el ambiente geológico comprendido por la Formación Coranzulí, caracterizado por mesetas ignimbríticas (Coira et al. 2004). El relieve se suaviza a tan solo un kilómetro al noreste del sitio, constituyendo de esta manera un área de confluencia entre dos paisajes contrastantes (Figura $4 \mathrm{a}$ y c). $\mathrm{Su}$ emplazamiento corresponde al sector bajo de la ladera de un afloramiento de ignimbritas, próximo a la llanura aluvial del Río Candado, ubicándose a una altura de $3.800 \mathrm{msm}$ (Figura $4 \mathrm{c}$ y d).

$\mathrm{RC} 2$ presenta una visualización media en relación al entorno (cima del afloramiento y llanura aluvial), al mismo tiempo que no cuenta con intervisibilidad con otros sitios cercanos.

Las manifestaciones rupestres en $\mathrm{RC} 2$ se ubican en un bloque de ignimbrita de grandes dimensiones 


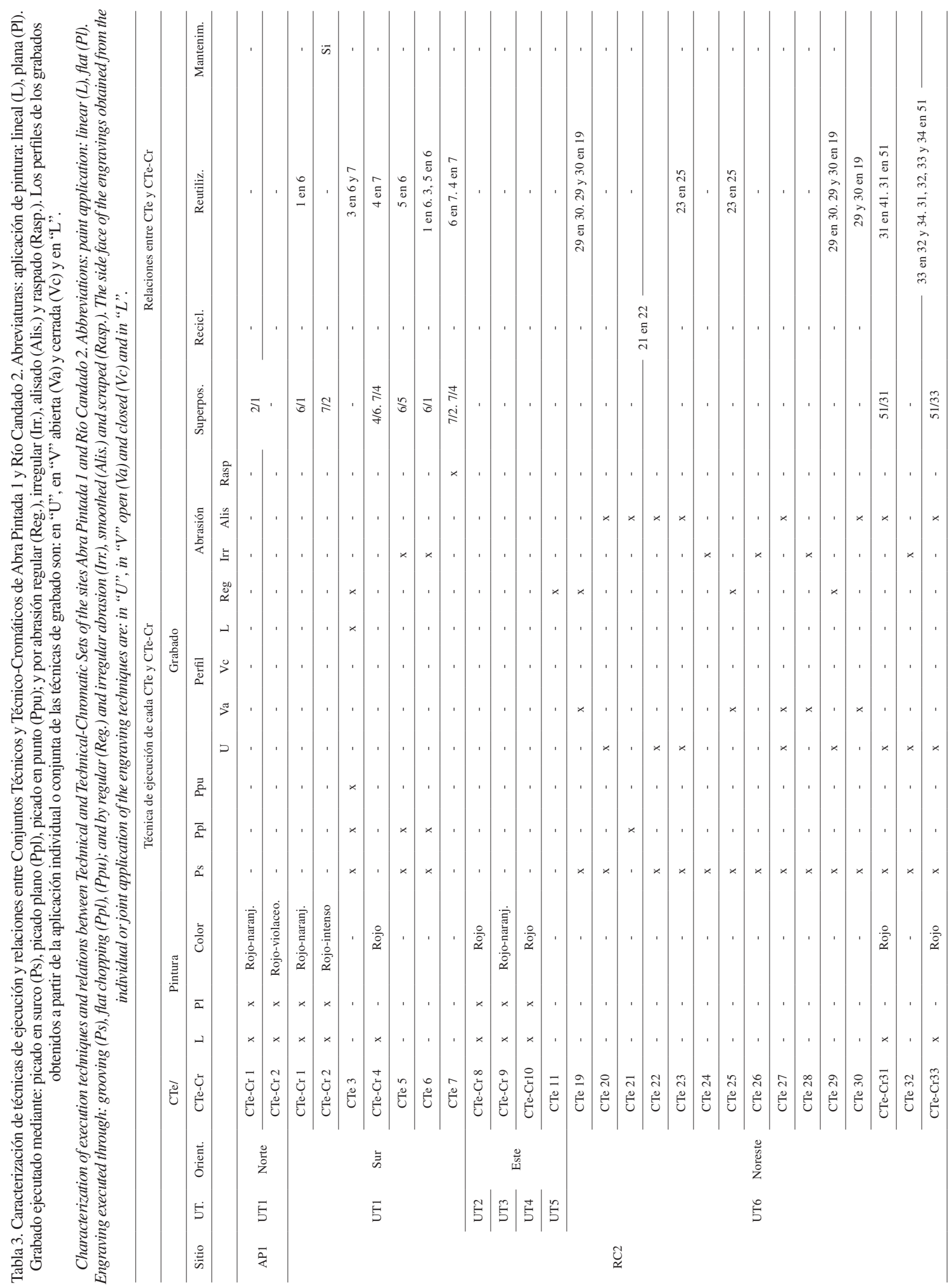




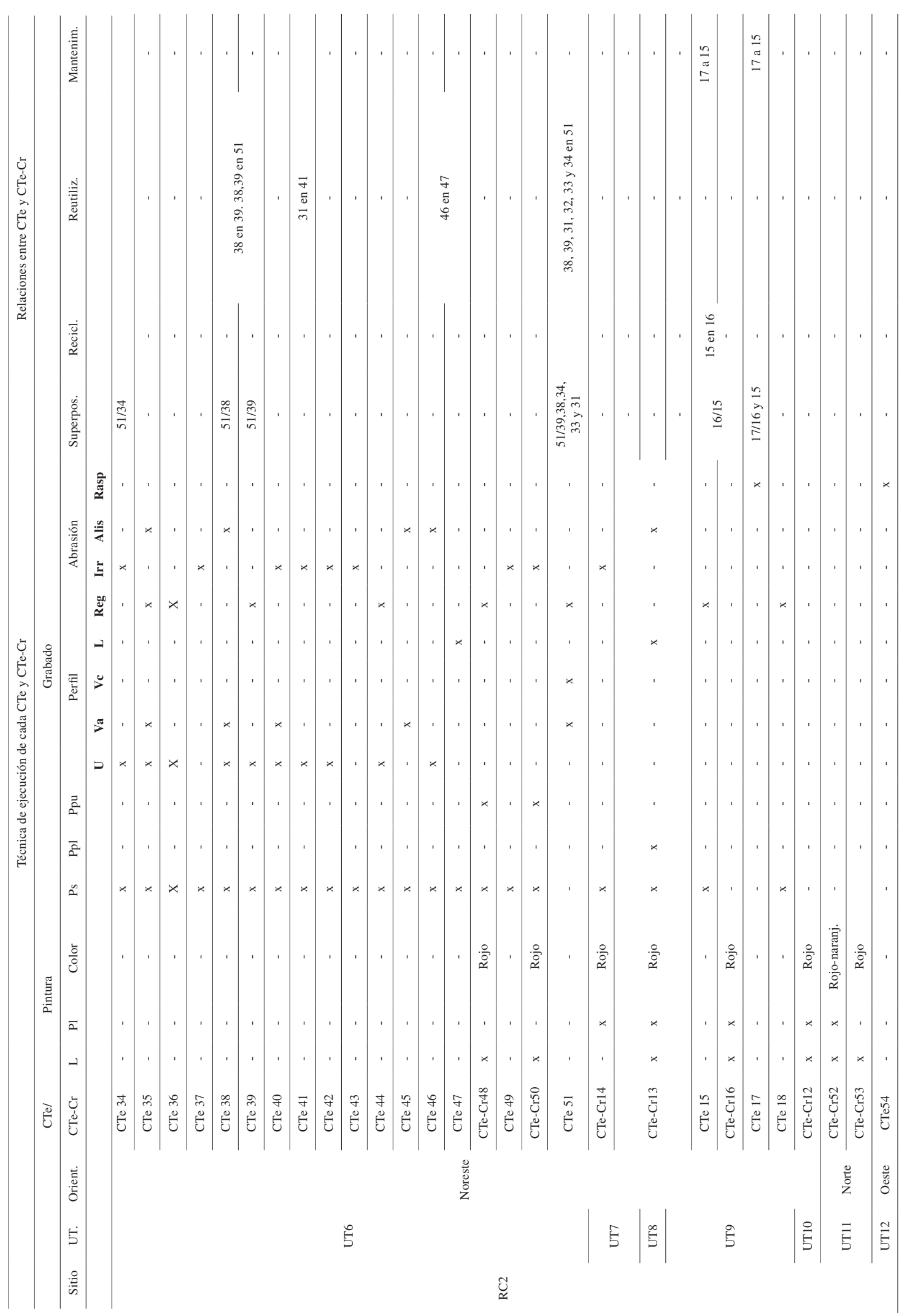





Figura 4. (a) Ubicación de RC2 y su relación con los sitios AP1 y T1. (b) Orientación de las UT de RC2. (c) Emplazamiento de RC2 y puesto actual cercano. (d) Paisaje de RC2. (e) Sector sur de RC2 con detalle de corral. (f) Morteros unidos por surcos grabados asociados a los paneles con arte rupestre.

(a) Location of RC2 and its relation to sites AP1 and T1. (b) Orientation of the TU of RC2. (c) Location of $R C 2$ and present temporary settlement. (d) Landscape of $R C 2$. (e) Southern sector of RC2 with corral detail. (f) Mortars joined by engraved grooves associated with panels with rock art.

(30 m x $25 \mathrm{~m}$ ), desprendido del sector superior de la ladera donde se localiza el afloramiento. Se encuentra diaclasado en dos partes, y se emplaza a unos $250 \mathrm{~m}$ hacia el este del Río Candado, en su margen izquierda (Figura 4 b y c). Se asocia a profundos morteros tallados en la roca, actualmente cubiertos por sedimento (Figura 4f), y cuenta además con varias pircas adosadas que conforman corrales de tamaños variables (Figura 4e). A unos 40 metros de RC2 se emplaza un puesto actual, que es utilizado durante el invierno para la pastura y el cuidado de los animales (Figura $4 \mathrm{c}$ y d).

En RC2 se registraron 12 UT que con fines analíticos fueron agrupadas en relación a su orientación general (Figura 4b). Las técnicas de ejecución registradas en RC2 son la pintura y el grabado. La aplicación de pintura se realizó mediante trazo lineal, plano y en punto, de colores rojo-anaranjado y rojo-violáceo (Tabla 3). Los grabados han sido ejecutados mediante el picado (en surco y plano) y la abrasión (Reg., Irreg., Alis., Rasp.), la mayoría de ellos combinando picado y abrasión con diversidad de perfiles (en "L", "U", "V" abierta y cerrada). Se registran pictograbados que combinan las diversas técnicas de grabado con la técnica de pintura. En la mayoría de los casos, ya sea que involucre el picado en surco o plano, se destaca una notable complejidad técnica que implica una gran inversión de tiempo y trabajo en la abrasión interna regular y el alisado para lograr un acabado uniforme del elemento.

De acuerdo a las características técnico-estilísticas, composicionales, diferencias cromáticas entre pinturas y de pátinas entre grabados, junto a las situaciones de superposición, mantenimiento, reutilización y reciclado identificadas en las $12 \mathrm{UT}$, se definieron 54 CTe y $\mathrm{CTe}-\mathrm{Cr}$, correspondientes a 54 eventos de ejecución (Tablas 2 y 3). En la orientación sur se encuentra la UT1 (Figura 5a-f), en la orientación este se registraron las UT2, UT3, UT4 y UT5 (Figura 6a, c-f), mientras que en la orientación norte se ubica la UT11 (Figura 6b). Con orientación noreste-este encontramos la mayor cantidad de manifestaciones rupestres, divididas en cinco unidades topográficas, desde la UT6 a la UT10 (Figuras 7, 8 y 9). Finalmente, con orientación oeste se encuentra la UT12.

RC2 evidencia una gran complejidad, y lo que inicialmente se presentaba como una mixtura de elementos y modos de hacer inconexos, al ser 




Figura 5. Manifestaciones rupestres de RC2 (sur). (a) Ubicación de los CTe y CTe-Cr registrados en UT1. (b) Matrix de relaciones técnico-estilísticas en la UT1. Abreviaturas: superposición (Sp), Reutilización (Rt), mantenimiento (Mt). (c) Detalle de superposición de CTe 6 sobre CTe-Cr1 y reutilización de este último en CTe 6. (d) Calco digital de CTe-Cr2. (e) Calco digital de CTe-Cr4. (f) Detalle de CTe 5 y CTe 6.

Rock art of RC2 (south). (a) Location of CTe and CTe-Cr recorded in TU1. (b) Matrix of technical-stylistic relations in TU1. Abbreviations: Superposition (Sp), Reuse (Rt), maintenance (Mt) (c) Superposition detail of CTe 6 over CTe-Cr1 and reuse of the latter in CTe 6. (d) Digital replica of CTe-Cr2. (e) Digital replica of CTe-Cr4. (f) Detail of CTe 5 and CTe 6.

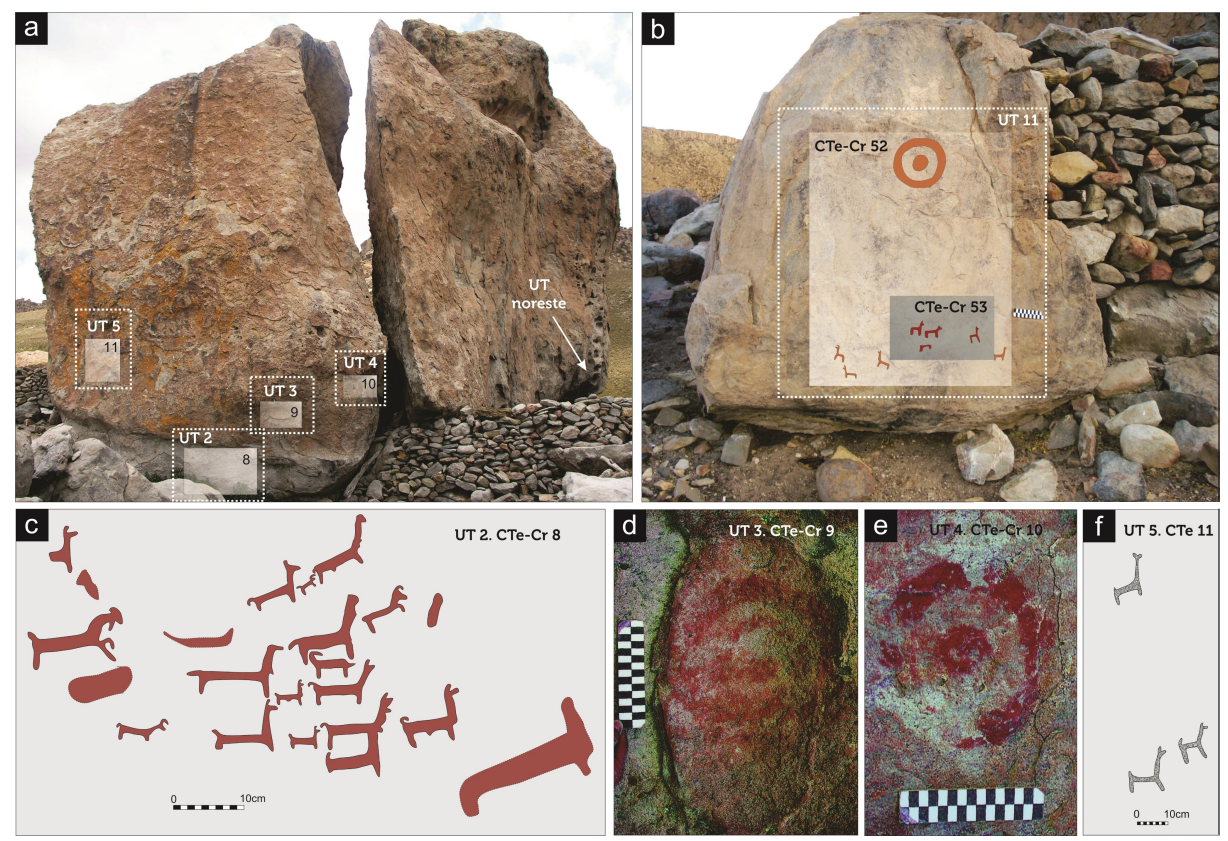

Figura 6. Manifestaciones rupestres de RC2 (este y norte). (a) Ubicación de UTs y CTe / CTe-Cr de orientación sur. (b) CTe-Cr 52 y 53 en UT11 orientación norte. (c) Calco digital de CTe-Cr8 de UT2. (d) Detalle de de CTe-Cr 9 en UT3. (e) Detalle de CTe-Cr 10 en UT4. (f) Calco digital de CTe11 en UT5.

Rock art of RC2 (east and north). (a) Location of TU and CTe / CTe-Cr of south orientation. (b) CTe-Cr 52 and 53 in TU11 northward. (c) Digital replica of CTe-Cr 8 in TU2. (d) Detail of CTe-Cr 9 in TU3. (e) Detail of CTe-Cr 10 in TU4. (f) Digital replica of CTe11 in TU5. 


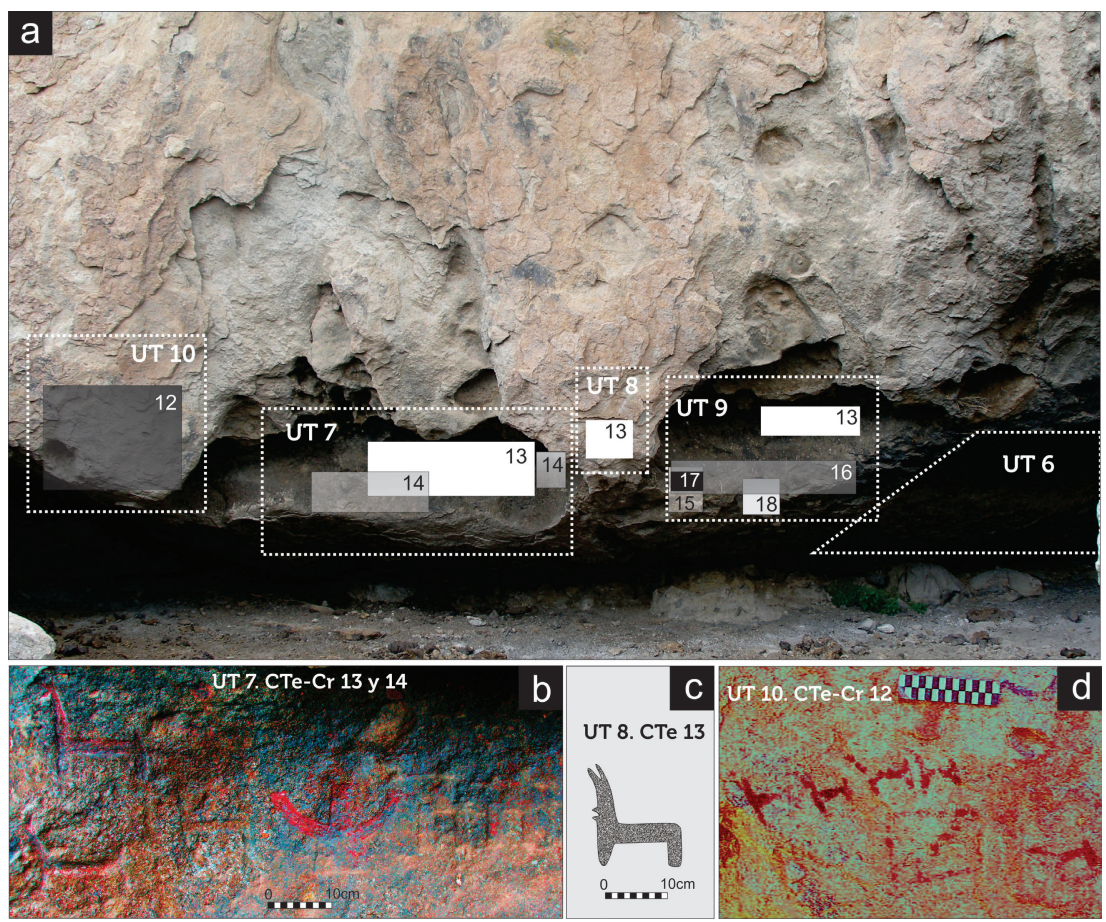

Figura 7. Manifestaciones rupestres de RC2 (noreste). (a) Ubicación de UTs y CTe / CTe-Cr de orientación noreste. (b) Detalle de CTe-Cr 13 y 14 en UT 7. (c) Calco digital de CTe 13 en UT8. (d) Detalle de CTe-Cr 12 en UT10.

Rock art of RC2 (northeast). a. Location of TU and CTe/CTe-Cr of northeast orientation. b. Detail of CTe$\mathrm{Cr} 13$ and 14 in TU 7. c. Digital replica of CTe 13 in TU8. d. Detail of CTe-Cr 12 in TU10.
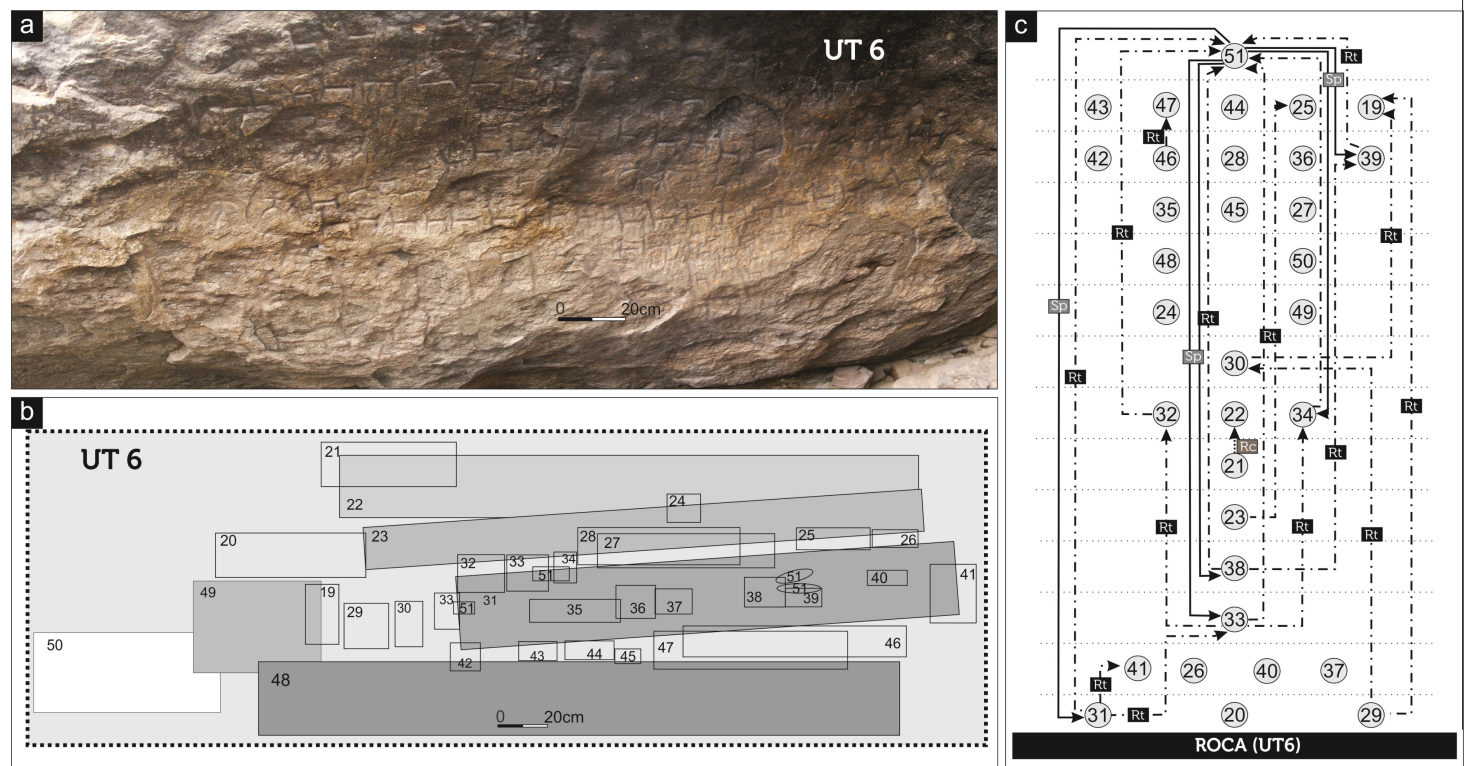

Figura 8. Manifestaciones rupestres de RC2 (UT6). (a) Detalle de UT6. (b) Ubicación de los CTe y CTe-Cr registrados en UT6. (c) Matrix de relaciones técnico-estilísticas en la UT6.

Rock art of RC2 (TU6). (a) Detail of TU6. (b) Location of CTe and CTe-Cr recorded in TU6. (c) Matrix of technical-stylistic relations in TU6. 


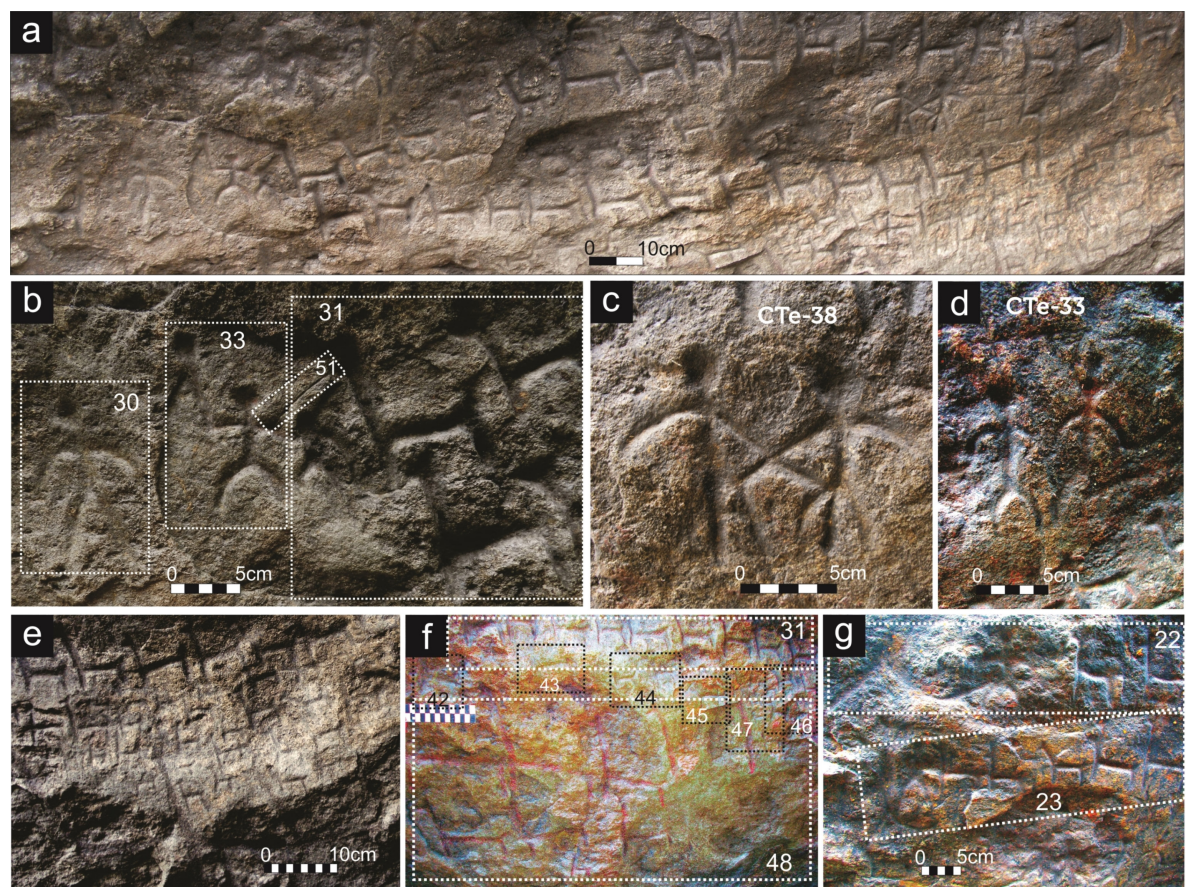

Figura 9. Manifestaciones rupestres de RC2 (UT6). (a) Detalle de temas caravanero y pastoril en UT6. (b) Detalle de CTe 30 y relaciones entre CTe 31, 33 y 51. (c) Detalle CTe 38. (d) Detalle de CTe 33. (e) Relaciones entre camélidos en caravanas y agrupados en rebaños (Conjuntos 31, 46, 47 y 48). (f) Relaciones entre camélidos en caravanas y camélidos con crías (Conjuntos 31, 42, 43, 44, 45, 46, 47 y 48). (g) Caravanas de camélidos con antropomorfo guía (CTe 22 y 23).

Rock art of RC2 (UT6). (a) Details of caravan and pastoral themes in TU6. (b) Detail of CTe 30 and relationships between CTe 31, 33 and 51. (c) Detail of CTe 38. (d) Detail of CTe 33. (e) Relations between camelids in caravans and grouped in herds (Sets 31, 46, 47 and 48). (f) Relations between camelids in caravans and camelids with offspring (Sets 31, 42, 43, 44, 45, 46, 47 and 48). (g) Camelid caravans with anthropomorphic guide (CTe 22 and 23).

analizados mediante la metodología propuesta en este trabajo pudieron ser evaluados teniendo en cuenta sus aspectos generales y particulares en la conformación del sitio. De este modo, se identificaron atributos de los conjuntos definidos que pueden ser vinculados a las dos modalidades estilísticas (MERH y MECiR) definidas para el período aquí considerado (Rodríguez Curletto y Angiorama 2016).

En RC2 se destaca la articulación de dos repertorios temáticos, uno de ellos relacionado a las prácticas pastoriles (Figuras 5c, d, f, 6c y 7b) y el otro a las actividades de tráfico caravanero (Figuras 7d, 8a, 9a y f), vinculándose entre ellos de diferentes modos, no solo entre unidades topográficas con orientaciones diferentes, sino también hacia el interior del espacio plástico de cada UT.

En la orientación noreste-este (UT6, UT9, UT10) se registran escenas de caravanas de camélidos con o sin personaje guía en la que se destaca, para la UT6, la cantidad y detalle en la manufactura de las tropas correspondientes a diferentes eventos de ejecución, que en la mayoría de los casos cuentan con diferentes grados de termoalteración ${ }^{5}$ (exposición al hollín) (Figura 8a).

En las orientaciones sur (UT1), este (UT2), noresteeste (UT6, UT7 y UT9) y norte (UT11), se registran temas vinculados a las prácticas pastoriles, en las que se destaca la presencia de animales dentro de corrales, hembras con sus crías, rebaños de camélidos con animales de diferentes tamaños (agrupados o en columnas), escenas de agresión entre camélidos machos posiblemente vinculado a momentos de la reproducción del rebaño, y camélidos aislados con caracteres que podrían ser vinculados a momentos en torno a su muerte (Figuras 5c, d, f y 6b).

En el sector noreste-este predomina cuantitativamente la figura del camélido en relación a la figura humana, aunque en general esta última presenta atributos que la resaltan dentro del espacio plástico (Lauricella 2016). Entre los camélidos (H2 y H2b) prevalece la vista hacia la izquierda y una actitud estática, sobre todo en aquellos casos que integran caravanas (Figura 9a y g). Sin embargo, los camélidos que han sido agregados 
posteriormente de manera aislada, o en grupos a modo de rebaños, en varios casos reutilizando cuidadosamente algunos camélidos de las caravanas, pueden presentar vistas, posturas y actitudes diversas (Figura 9e). En este sector noreste-este, la presencia de la figura humana articula ambos repertorios temáticos y se registra de tres modos distintos: (1) aislada y en una posición central dentro de la UT, (2) vinculada a camélidos, y (3) asociada a otras figuras humanas.

En la UT7 se destaca una figura humana aislada con los brazos alzados en una posición central y conjugando dos patrones diferentes, el patrón G3 y el H5 o antropomorfo "T" (Figura 7b). Para la segunda situación, se observa la figura humana (patrón H1) no solo como guía de las recuas de llamas (Figura 9a, b y g), sino también en algunos casos asociados a no más de dos camélidos de diferentes tamaños ubicados en fila a su lado. Finalmente, para la tercera situación se registran figuras humanas (patrón H1), agrupadas de a dos o más individuos tomados por sus manos, en algunos casos portando un objeto en una de sus extremidades superiores, con adornos cefálicos y/o con la presencia de falo (Figura 9c yd).

En las relaciones establecidas entre los diferentes CTe y CTe-Cr de RC2, se observa en la mayoría de los casos una intencionalidad de mantener y/o actualizar los temas tanto pastoriles como caravaneros (Tabla 1; Figura 8 b y c). Solo en la UT1, de orientación sur, se observan superposiciones totales sobre motivos previos que en general corresponden a conjuntos de la MERH sobre la MECiR, pero aun así continúan reutilizando los motivos previos en temas pastoriles similares (Figura 5 a, b y c). En el resto de los casos, las superposiciones registradas no invaden ni cambian el sentido del motivo que intervienen, sino que consiste en superposiciones parciales que agregan algún detalle para que ese motivo pueda ser ubicado en un contexto de significación relativamente "nuevo" por medio de una reutilización, pero que de todos modos mantiene o actualiza el tema que interviene (Figura 8 b y c). De este modo, se observa una intención de reforzar ciertas relaciones (por ejemplo, agregar una rienda entre el antropomorfo guía y el primer camélido de la caravana), o algunos caracteres de ciertos elementos (por ejemplo, aplicación de pintura roja sobre ciertos sectores de un grabado), pero en ningún caso se reciclan totalmente en contextos de significación y temas radicalmente diferentes a los que plantea originalmente el diseño intervenido. En el mismo sentido, se observan yuxtaposiciones que permiten la participación de ciertos elementos en dos temas diferentes. Ejemplo de ello, es la ubicación de varios camélidos de menor tamaño a modo de rebaño yuxtapuestos a camélidos de mayor tamaño que conforman las caravanas. De este modo, si bien surge una reutilización de ciertos elementos en un nuevo tema (p.ej., de la caravana al rebaño), se destaca la intencionalidad de mantener dicho elemento en ambos contextos de significación sin evidenciar la invalidación de uno sobre el otro (Figura 9e).

En el diagrama de relaciones técnico-estilísticas (Figura 10) las elipses A, B, C y D vinculadas a la MECiR, presentan camélidos del patrón $\mathrm{H} 2$, muchos de ellos vinculados a la variante $\mathrm{H} 2 \mathrm{~b}$, figuras humanas de los patrones $\mathrm{G} 3 / \mathrm{H} 5$ y H1${ }^{6}$, y figuras geométricas, tales como círculos concéntricos y rectángulo con escalerado interno (Tabla 1; Figuras 6d, e y 7d). Las técnicas de ejecución son la pintura (variantes del rojo), el pictograbado, y una gran diversidad de grabados con diversos perfiles, todos ellos con diferentes grados de abrasión en el interior y bordes, lo que implica un acabado muy uniforme, con una alta inversión de tiempo y trabajo en su ejecución (Tabla 3; Figura 2).

Las elipses concéntricas E, F y G, vinculables a la MERH, presentan camélidos del patrón H3, figuras geométricas de líneas rectas paralelas dispuestas en columnas, sin la presencia de la figura humana (Tabla 2; Figuras $5 b$, c, f y 6f). Las técnicas de ejecución son principalmente el grabado (picado en surco, plano y raspado), con el interior y los bordes muy irregulares y sin evidencias de abrasión interna, con tan solo algunos motivos pintados en rojo (Tabla 3 ).

La gran cantidad de eventos de ejecución, y los tipos de relaciones detectadas entre los diferentes $\mathrm{CTe}$ y CTe-Cr en RC2, reafirman por una parte, diferencias técnicas entre la MERH y la MECiR; mientras que por otra parte, hacia el interior de la MECiR, evidencian una continuidad técnica-conceptual a través del tiempo, más allá de algunas diferencias puntuales en la configuración de ciertos elementos.

\section{Interpretación y Articulación de los Resultados con Paisajes Rupestres de la Microrregión}

Como mencionamos anteriormente, el paisaje de AP1 ofrece un punto de inflexión entre ambientes geológicos y fisiografías diferentes de la llanura aluvial abierta, con la zona cumbral de los afloramientos de ignimbrita donde se encuentran los puestos, vegas y lagunas de altura. Esta área con abundantes recursos de altura, justamente constituye el sector de ingreso occidental a las quebradas de la Sierra de Carahuasi, que comunican directamente este sector mesetiforme con el interior de la cuenca de Pozuelos.

Si recordamos que estas manifestaciones rupestres de AP1 están dispuestas al borde de una senda de tránsito que comunica la cuenca de Pozuelos, hacia el este con la región lacustre altoandina, y Atacameña al oeste; se destaca entonces la dirección prácticamente paralela de las caravanas a la inclinación de la base de la UT, y el sentido de las mismas con vista hacia el este (CTe-Cr1) y hacia el oeste (CTe-Cr2), lo cual podría vincularse a la 


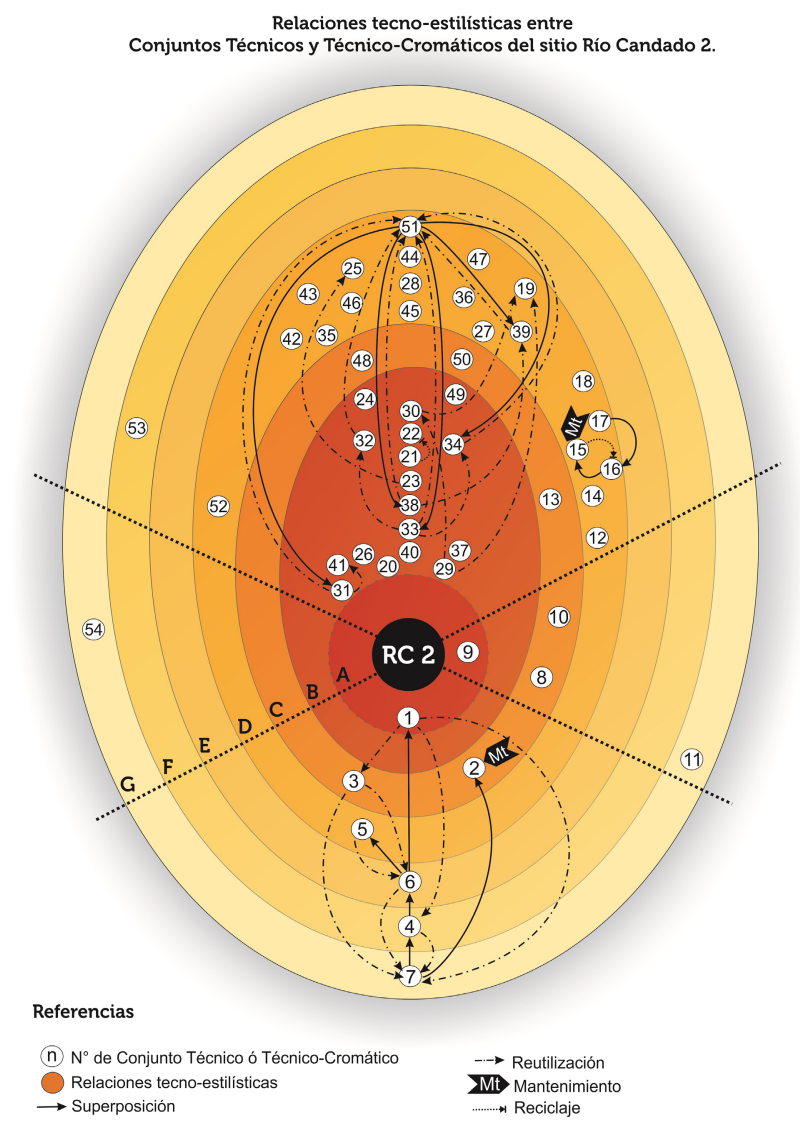

Figura 10. Matriz global de relaciones técnico-estilísticas de RC2.

Overall matrix of technical-stylistic relations of $R C 2$.

situación de descenso de las tropas por esta ladera cuando se dirigen hacia el interior de la cuenca, y de ascenso cuando se dirigen hacia Orosmayo-Río Grande de San Juan, lagunas altoandinas y Atacama (Figura 3b).

Los dos eventos de ejecución identificados en AP1 reflejan un manejo técnico, temático y composicional muy similar entre ellos, no solo por la presencia de caravanas acompañadas o guiadas por una figura humana, sino también porque en cada CTe-Cr se repite la figura del antropomorfo "T" (patrón H5) de mayor tamaño, ubicado en una posición destacada y superior a modo de figura "protectora" de las caravanas que se disponen por debajo, lo cual implica que no solo el tema se mantiene y actualiza en el tiempo, sino también que las relaciones establecidas entre los diferentes agentes performados (sensu Butler 2002, 2007) pueden ser analizadas como un proceso de larga duración (Braudel 1984). En este sentido, es interesante destacar la ejecución sincrónica de los antropomorfos " $T$ " con las caravanas de camélidos en ambos conjuntos (Figura 3d).

Si bien no es posible precisar cuánto tiempo transcurrió entre el primer y segundo evento de ejecución en AP1, podemos pensar en una recurrencia en el uso de esta ruta este-oeste que podría estar retroalimentando (a través de las direcciones y sentidos de los motivos), justamente ese movimiento físico-corporal en ambos sentidos para el ingreso/egreso a la cuenca de Pozuelos.

Además de la evidencia del tráfico caravanero sugerida por los motivos de caravanas de llamas con su guía en ambos CTe-Cr, la presencia de camélidos posiblemente descansando en el CTe-Cr2 (Figura 11a y b) refuerza la significación propuesta desde el estudio del paisaje, en relación a la constitución de este "lugar" como un segmento de ruta del tráfico regional de medialarga distancia (Nielsen 2017), particularmente como un sitio para el pernocte de los arrieros y sus recuas, que pudieron establecer sus jaranas o campamentos en el ciénego que se encuentra a unos $50 \mathrm{~m}$ hacia el noreste de AP1, donde se emplazan los dos recintos circulares asociados a un corral, y donde se ubica el puesto pastoril actual (Figura 3a y c).

Lo mencionado sobre las propiedades confluentes de este paisaje, coincide con las características propuestas desde la etnoarqueología en torno a la 

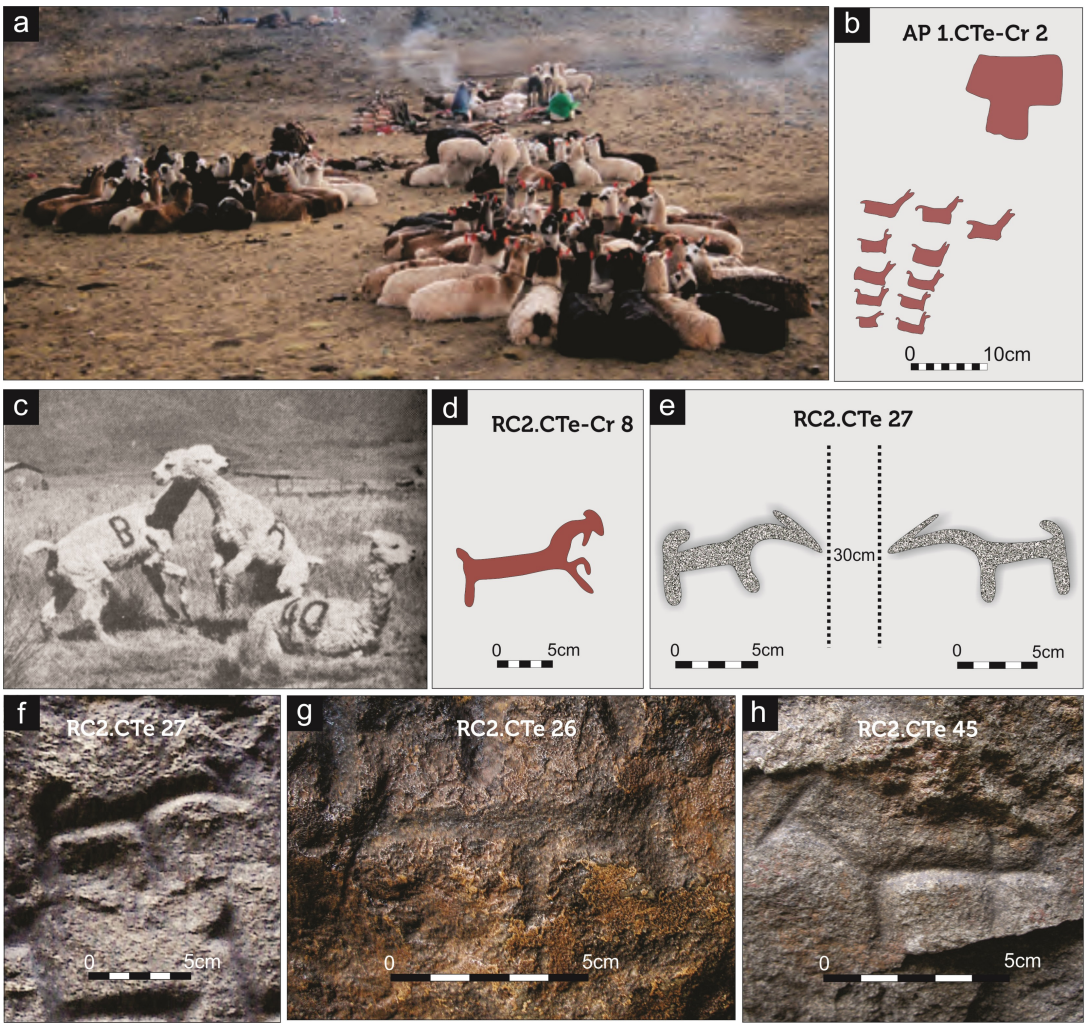

Figura 11. (a) Sitio de descanso de caravanas de llamas en la feria anual de Santa Catalina, Argentina (Nielsen 2013:396, figura 16.4), nótese la disposición de las llamas en situación de descanso. (b) Detalle de CTe-Cr2 de AP1 con camélidos sin extremidades, posiblemente en situación de descanso. (c) Enfrentamiento entre camélidos machos para establecer la dominancia sexual en el rebaño (Sumar 1991:124, figura 4.6), nótese la disposición y actitud de sus cuerpos. (d), (e) y (f) Detalle de CTe-Cr 8 y CTe 27 de RC2 con camélidos enfrentados (actitud agresiva, cuello curvo y cola hacia arriba, y orejas hacia atrás). (g) y (h) Detalle de camélidos con cuello y cabeza recta en "T", CTe 26 y CTe 45 de RC2 respectivamente.

(a) Resting-place of llama caravans in Santa Catalina annual fair, Argentina (Nielsen 2013:396, figure 16.4), note the arrangement of the llamas in resting posture. (b) Detail of CTe-Cr 2 of AP1 with camelids without limbs, possibly in a resting posture. $c$. Confrontation between male camelids to establish sexual dominance in the herd (Sumar 1991:124, figure 4.6), note the arrangement and attitude of their bodies. $(d),(e)$ and $(f)$ Detail of CTe-Cr 8 and CTe 27 of RC2 with camelids confronting (aggressive attitude, curved neck and tail up, and ears backwards). ( $g$ ) and (h) Detail of camelids with straight neck and head in "T", CTe 26 and CTe 45 of $R C 2$ respectively.

ubicación de marcas territoriales o mojones sobre el camino, vinculados a lugares de descanso transitorio de la recua (realero o jarana), y que pueden tener algún rol o implicancia en el ceremonialismo del caravaneo (Gabelman 2015; Lecoq 1987; Lecoq y Fidel 2003; Nielsen 1997, 1997/1998, 2013, 2017).

Por otra parte, el paisaje de RC2, con una buena oferta de agua, pasturas, leña y reparos (naturales y estructuras), constituye un paisaje coyuntural en tres aspectos diferentes: (1) desde la fisiografía (punto de inflexión) que articula dos paisajes contrastantes del relieve suave del fondo de la quebrada (donde se ubica el río homónimo), con los altos farallones de ignimbritas que lo encajonan y reparan al este y al oeste; constituyendo de este modo, un punto clave de ingreso/ egreso desde esta quebrada del Río Candado hacia el Río Cincel que discurre en el fondo del bolsón de
Pozuelos; (2) por la articulación de dos repertorios temáticos vinculados al tráfico caravanero y a las prácticas pastoriles; y (3) por la confluencia de las modalidades estilísticas definidas para la zona para momentos de los Desarrollos Regionales (MECiR y MERH), con una gran complejidad técnica y diacrónica hacia el interior de la MECiR.

En relación a las prácticas pastoriles, las investigaciones demuestran que en regiones áridas con recursos fragmentados, tal como la puna jujeña, una de las estrategias más viable es la del pastoralismo, no tanto a modo de táctica productiva sino como modo de vida (Flores Ochoa 1983). En estos ambientes la práctica adquiere un carácter extensivo, con alta movilidad espacial y un patrón de residencias múltiples (con rotación estacional) fundamental para proveer alimento, cuidado y beneficios para la reproducción 
a los rebaños, así como para el aprovechamiento de diferentes ecozonas y el fortalecimiento, a través de la actividad ritual, del vínculo entre los animales y sus pastores (Dransart 2011; Flores Ochoa 1983, 1974; Galaty y Jonhnson 1990; Medinaceli 2005).

Las características de RC2 en relación al paisaje, al contexto arqueológico, y su alto potencial para el desarrollo de prácticas pastoriles, nos llevan a pensar que pudo corresponder a un puesto de pastoreo temporario, reocupado en la actualidad con la misma finalidad. Dicho puesto temporario pudo haberse articulado directamente con el sitio T1, un caserío agrícola-pastoril relevante de la microrregión que se configura como una base residencial permanente ubicado a solo $3,5 \mathrm{~km}$ hacia el sureste de RC2, en una quebrada paralela a la del Río Candado. Tabladitas 1 se emplaza en el fondo de la quebrada homónima, cercano a un curso de agua que desemboca en el Río Cincel. Cuenta con terrazas agrícolas, corrales y estructuras habitacionales, cerámica en superficie, morteros dispersos y abundantes palas líticas fracturadas. $\mathrm{El}$ arte rupestre, ejecutado mediante la técnica de pintura roja, se ubica en bloques de ignimbrita, articulado con estructuras de vivienda, y cuenta con motivos de camélidos aislados, agrupados, dispuestos en columnas y figuras humanas, entre las que se destacan las del patrón H5 (Figura 13a, d y e), todas ellas vinculables a la MECiR (Rodríguez Curletto 2014). Un fechado radiocarbónico ubica la ocupación de uno de los recintos domésticos de T1 en 1312-1432 cal. DC, $1 \mathrm{~s}^{7}$.

En relación al tráfico caravanero, siguiendo algunos aspectos planteados desde la etnoarqueología sobre los atributos del paisaje y el contexto arqueológico, consideramos que $\mathrm{RC} 2$ se constituye como un paisaje relevante en relación a la ritualidad vinculada al caravaneo (como veremos más adelante). En este sentido, los repertorios temáticos del arte rupestre presentes en el sitio refuerzan estas propuestas sobre la confluencia en RC2 de ambas prácticas (caravanera y pastoril).

Dentro del repertorio caravanero se encuentran diferentes eventos de ejecución correspondientes a recuas de camélidos, en la mayoría de los casos con la presencia de un personaje guía al inicio de cada caravana. En cada uno de estos motivos, no solo se destacan las complejas técnicas de grabado implementadas, sino también la estandarización estilística y conceptual compartida por los diferentes eventos de ejecución vinculados a la MECiR (Figuras 7d, 9a, f y g).

El repertorio temático pastoril (compartido por la MERH y la MECiR), cuenta con la manifestación de camélidos agrupados de diferentes tamaños, en corrales, en rebaños, hembras con crías aisladas o encerradas en corrales, camélidos en actitud de agresión, camélidos atados y otros con diferentes vínculos a la figura humana (Figuras 5, 6, 7, 8 y 9). La misma complejidad y continuidad conceptual mencionada en las técnicas de ejecución del tema caravanero se repite en el tema pastoril vinculado a la MECiR.
La gran cantidad de CTe y CTe-Cr diferenciados en $\mathrm{RC} 2$ en general, y en el sector noreste-este en particular, junto a la articulación de temas diferentes (caravanero y pastoril), evidencia múltiples reutilizaciones de este paisaje que estarían gravitando en un manejo compositivo y conceptual que perdura en el tiempo a través de distintos eventos de ejecución ( $\mathrm{N}=54)$, como si se tratara de un proceso de larga duración que es repetido y actualizado a través del tiempo, al menos dentro del lapso temporal de los Desarrollos Regionales (Figuras 5a, b, 7a, 8b y c, 10).

Las investigaciones realizadas en puna meridional y en algunos sitios del norte de Chile, proponen que el arte rupestre vinculado a prácticas caravaneras y pastoriles no suelen compartir el mismo emplazamiento, debido a que las características de los paisajes seleccionados para cada caso serían diferentes (Aschero 1998 [1996], 2000; Martel 2010). Algunos autores destacan que en los casos en que esto ocurre, se registra una ambigüedad del registro arqueológico, que correspondería a puestos de pastoreo que han sido utilizados como refugio temporal de caravaneros con sus recuas, y entonces refieren una modificación del contexto arqueológico "original" vinculado al pastoreo (Berenguer 2004; Martel 2011; Nielsen 1997, 2003). Incluso plantean que en una UT con el tema caravanero, se pueden registrar caravanas con características estilísticas diferentes, sugiriendo diversidad de autores implicados en su ejecución (Aschero 1998 [1996], 2000; Berenguer 2004; Martel 2010; Martel et al. 2012). En relación a este punto, resulta interesante destacar que en RC2 ocurre lo opuesto, no solo confluyen ambos temas en el mismo sitio (incluso en las mismas UT), sino que además se observa la recurrencia de un entramado complejo de prácticas rituales pastoriles y caravaneras con una marcada lógica articulada a través del tiempo. Además, tal como hemos fundamentado anteriormente, todos los eventos de ejecución identificados para la temática del caravaneo y la mayoría de los identificados para el tema pastoril, comparten un mismo conocimiento compositivo vinculado a la MECiR.

Estos aspectos sugieren por una parte, que las prácticas pastoriles y caravaneras en este sector de la puna se encuentran muy vinculadas entre sí de modo cohesivo y recurrente, y por otra parte, que no podemos segregar como grupos diferentes a los ejecutantes del arte rupestre caravanero del pastoril, sino por el contrario, pensar en un paisaje y una ruta de trafico utilizada y protegida a través del tiempo, por pastores caravaneros locales que en diferentes momentos del año desarrollan ambas actividades y comparten un mismo conocimiento técnico y conceptual en la producción del arte rupestre tanto pastoril como caravanero 8 .

Por supuesto que no descartamos que caravaneros no locales puedan haber transitado por estos caminos en diferentes momentos y haber utilizado estos mismos sitios como puntos relevantes dentro del entramado 
de rutas articuladas con el $\mathrm{PuR}^{9}$. Sin embargo, lo que podemos asegurar hasta el momento de acuerdo a lo aquí presentado, es que el arte rupestre caravanero registrado en $\mathrm{AP} 1$ y $\mathrm{RC} 2$ correspondería íntegramente a una modalidad estilística de producción local claramente sostenida en el tiempo.

A partir de lo mencionado, proponemos que en el sur de Pozuelos, los sitios RC2 y AP1 (con buena oferta de agua, forrajes, reparos, ubicación estratégica en puntos fisiográficos y ambientales de inflexión y, alejados de áreas densamente pobladas) constituyen paisajes rupestres coyunturales, aunque con atributos, sentidos y relaciones diferentes entre sí. Las manifestaciones rupestres y la configuración de sus paisajes generaron la "emergencia" de "lugares" (sensu Ingold 2000) distintos, vinculados a las prácticas caravaneras en AP1 $\mathrm{y}$, a las prácticas pastoriles y caravaneras en $\mathrm{RC} 2$, sitio probablemente vinculado a T1 como base residencial.

Estos "lugares" así constituidos se habrían articulado con lo que consideramos el asentamientoeje de esta microrregión: el Pukara de Rinconada y sus mesadas aledañas (Figura 12a y c). Este sitio se emplaza sobre altas mesetas de ignimbrita, y está conformado por un complejo conglomerado de estructuras en la cima de una de ellas, chullpas en las bases de los farallones, y una gran cantidad y diversidad de manifestaciones rupestres de diferentes cronologías (Albeck y Ruiz 2003; Alfaro de Lanzone 1969; Alfaro de Lanzone y Suetta 1970, Ruiz y Chorolque 2007). En el Pukara de Rinconada confluyen también las dos modalidades estilísticas referidas (MERH y MECiR), articulándose de diferentes modos las temáticas pastoriles y caravaneras (Figura 12c, d y e). Este asentamiento, además de configurarse como un paisaje coyuntural destacado, con alta visualización y acceso físico restringido que le permite un gran control físico y visual de gran parte de la cuenca de Pozuelos, constituye también un punto neurálgico para las rutas de tránsito y tráfico de la microrregión (Rodríguez Curletto 2014) conformándose posiblemente como base llamera y terminal de carga-descarga para caravanas que habrían llegado desde diferentes lugares (sensu Nielsen 2017).

Si bien los atributos del paisaje y del contexto arqueológico son diferentes en RC2 y en PuR, es interesante destacar que comparten entre sí varios atributos en la composición del arte rupestre. En

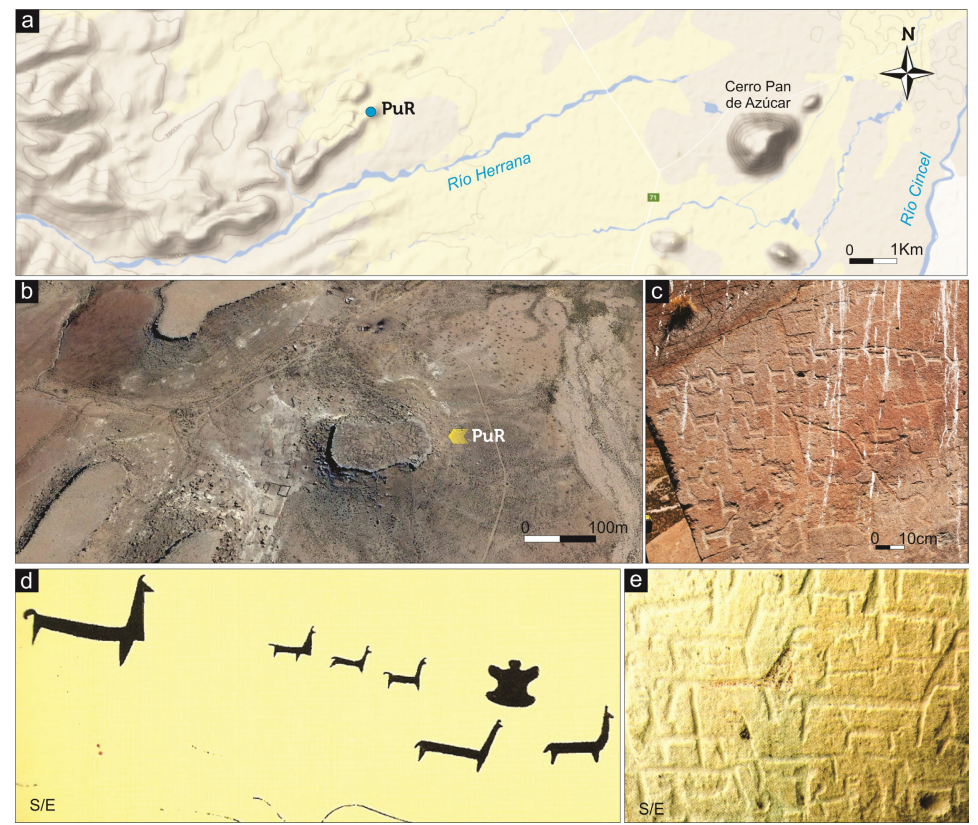

Figura 12. Pukara de Rinconada. (a) y (b). Ubicación y emplazamiento de PuR. (c) Articulación de temas caravaneros y pastoriles en la misma UT. (d) Articulación de patrón H5 con ambos repertorios temáticos (Ruiz y Chorolque 2007:137, figura 9). (e) Detalle de camélidos enrebaño vinculables a la MECiR (Ruiz y Chorolque 2007:77, figura 22)

Pukara de Rinconada. (a) and (b) Location and emplacement of PuR. (c) Articulation of caravan and pastoral themes in the same TU. (d) Articulation of pattern H5 with both thematic repertoires (Ruiz and Chorolque 2007:137, figure 9). (e) Detail of camelids in herds associated to the MECiR (Ruiz and Chorolque 2007:77, figure 22). 
ambos sitios se registra: (1) la articulación de los repertorios temáticos (caravanero y pastoril) con la presencia de motivos de círculos concéntricos; (2) una alta recurrencia de reutilizaciones de elementos y motivos entre temas; (3) la articulación de la MERH y la MECiR con una baja proporción de superposiciones y reciclados entre ellas; (4) una complejidad de la MECiR en términos sincrónicos, reflejada en una alta inversión de trabajo y tiempo en la ejecución de diversas técnicas de grabado, mientras que en términos diacrónicos, la inversión se ve reflejada en los múltiples eventos de ejecución registrados en un mismo espacio plástico.

Más allá de estos aspectos compartidos, mientras el PuR presenta una vasta cantidad y variedad de motivos de la MERH, en RC2 solo se registran cinco conjuntos técnicos vinculables a la MERH de un total de 54 Conjuntos $\mathrm{Te}$ y $\mathrm{Te}-\mathrm{Cr}$ registrados en el sitio (Figuras $10,5 b$, c, e y 6 f). Esto implica que estos dos sitios tan diferentes en el entramado de paisajes y contextos arqueológicos en esta microrregión, plantean desde el arte rupestre, varios vínculos técnico-estilísticos en torno a la MECiR pero no en torno a la MERH.

Hasta aquí entonces, los sitios presentados sugieren la circulación de personas, bienes, animales y conocimientos por medio de dos tipos de movilidad: la trashumancia pastoril y el tráfico caravanero. Prácticas que parecen haber sido recurrentes a través del tiempo, evidenciando un reúso de espacios tanto en las UT en particular, como de los paisajes en general.

¿Es posible visualizar aspectos de la ritualidad de dichas prácticas en estos paisajes rupestres? Más allá de la función socio-económica que puedan implicar las prácticas pastoriles y el tráfico caravanero, diferentes autores sostienen que ambas habrían involucrado también diferentes acciones y esferas rituales, algunas de las cuales son referidas por trabajos etnoarqueológicos, arqueológicos, etnográficos e históricos para la región andina centro meridional (Aschero 2000; Bugallo 2010; Dransart 2002; Flores Ochoa 1974, 1983; Gabelman 2015; Lecoq 1987; Lecoq y Fidel 2003; Martel 2011; Martel y Aschero 2007; Nielsen 1997/1998, 2013, 2017).

Esta ritualidad se conforma de diferentes modos en relación al pastoreo de animales, como pueden ser el señalakuy ${ }^{10}$ (o rito de marcaje) y el ritual del empadre o jila jikxata uywa ch'uwa ${ }^{11}$ que ocurren alrededor del Carnaval, entre diciembre y febrero. Luego, durante los meses de invierno (desde junio hasta fines de agosto), se realizan ritos en torno a los viajes de caravaneo ${ }^{12}$, desde su inicio, durante su desarrollo, y al finalizar los mismos, cerrando un ciclo de ritualidad anual alrededor de septiembre, cuando los caravaneros retornan a su hogar (Berenguer 2004; Briones et al. 2005; Lecoq y Fidel 2003; Martel 2011; Nielsen 1997/1998; Pimentel 2009).
Estas ceremonias constituyen momentos importantes que refuerzan el rol sagrado de la llama y su relación especial con el pastor, y buscando renovar la relación armónica de la comunidad, la familia y el pastor con la Pachamama, con los seres tutelares Apus, Achachilas, Mamas, Illas, Uywiris, Mallkus, entre otros. De ese modo se pretende lograr la protección, fertilidad y bienestar de los rebaños, pastores, sus familias y la vida comunitaria en general, todos ellos dependientes de ese frágil equilibrio que se establece con sus seres tutelares (Dransart 2002; Lecoq y Fidel 2003; van Kessel y Llanque Chana 2004), situación que puede ser interpretada como la existencia de relaciones de saber-poder (sensu Foucault 2015) entre estos seres tutelares y las comunidades.

Numerosas evidencias registradas en los cuatro sitios aquí presentados conforman también posibles contextos vinculados a prácticas rituales (Flores Ochoa 1974; Lecoq y Fidel 2003; Nielsen 1997/1998; van Kessel y Llanque Chana 2004). En relación al paisaje y contextos observamos: (1) las estrategias de elección de los paisajes de AP1 y RC2 donde se ejecuta el arte rupestre, haciendo referencia a la selección de puntos de inflexión o de ruptura del terreno, cercanos a aguadas o ríos, acceso visual y/o físico a formaciones elevadas y destacadas en el terreno (mallkus destinatarios de las rogativas); (2) la orientación cardinal hacia el noreste-este en RC2 que prevalece en las UT con motivos de caravanas; (3) el contexto arqueológico en RC2, con evidencia de fogones recurrentes en un mismo espacio, morteros comunitarios, refugios capaces de albergar a numerosas personas, y la existencia de kanchas (corrales posiblemente vinculados al cruzamiento y reproducción de los animales); (4) presencia de mojones y apachetas tanto en AP1 como en RC2, algunos de ellos alineados a rasgos destacados en el paisaje. En relación al arte rupestre, se destacan: (1) las complejas técnicas de ejecución en RC2 (considerable inversión de tiempo, trabajo y conocimiento técnico que involucran la mayoría de las manifestaciones de la MECiR); (2) continuidad conceptual, y en los modos de hacer y/o actualizar relaciones entre los diferentes motivos y temas plasmados tanto en AP1 como en RC2; (3) configuración de las manifestaciones: (a) figura humana del patrón $\mathrm{H} 5$ en posición central y escala destacada en los CTe-Cr 1 y 2 de AP1 vinculada al tema caravanero (Figura 3d), la figura humana en RC2 portando objetos (cetro, arma, ¿objeto ritual?), con adorno cefálico y/o presencia de falo, que articula ambos repertorios temáticos (pastoril y caravanero) y que integra escenas de antropomorfos tomados de las manos (¿ceremonias?) con manufactura progresiva (Figura 9a, b, c, d y g), (c) figura humana de brazos alzados en RC2 (patrón H5G3) (¿yatiri u oficiante del rito?) también en posición central y escala destacada en temas caravanero y pastoril 
(Figura13 b, c, fy g), (d) camélidos en RC2 en postura de agresión (aislados o enfrentados), posiblemente machos enfrentados que harían referencia a momentos de reproducción del rebaño (Latcham 1922; Súmar 1991) o a ceremonias del inicio del rito de empadre (jila jikxata uywa ch'uwa), que ocurren justamente dentro de las kanchas (corrales asociados a dichas manifestaciones) (Figura 11d - f), (e) camélidos en RC2 aislados con caracteres vinculables a momentos en torno a su muerte (¿willancha?) (Figura 11g y h).

Si bien estos aspectos, tan solo constituyen un punto de partida a seguir indagando, nos detenemos en un elemento en particular, que consideramos tendría relación con dicha ritualidad transponiéndose en paisajes y contextos vinculados al caravaneo, a las prácticas pastoriles y en aquellos paisajes en los que ambas prácticas se entrelazan. Nos referimos a la figura humana del patrón H5, o también denominado antropomorfo "T" (Aschero 2000; López Campeny y Martel 2014). Este elemento y sus variantes se registran en AP1 asociado a las caravanas de llamas en los dos eventos de ejecución, en RC2 en los paneles con orientación noreste que justamente articulan los temas pastoril y caravanero, en el PuR también

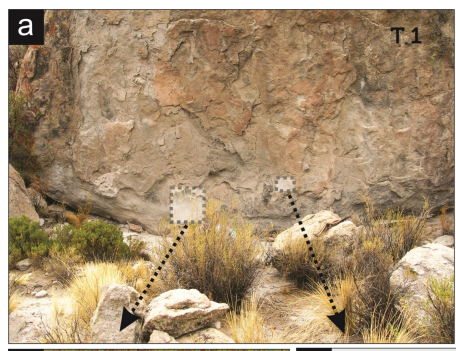

d

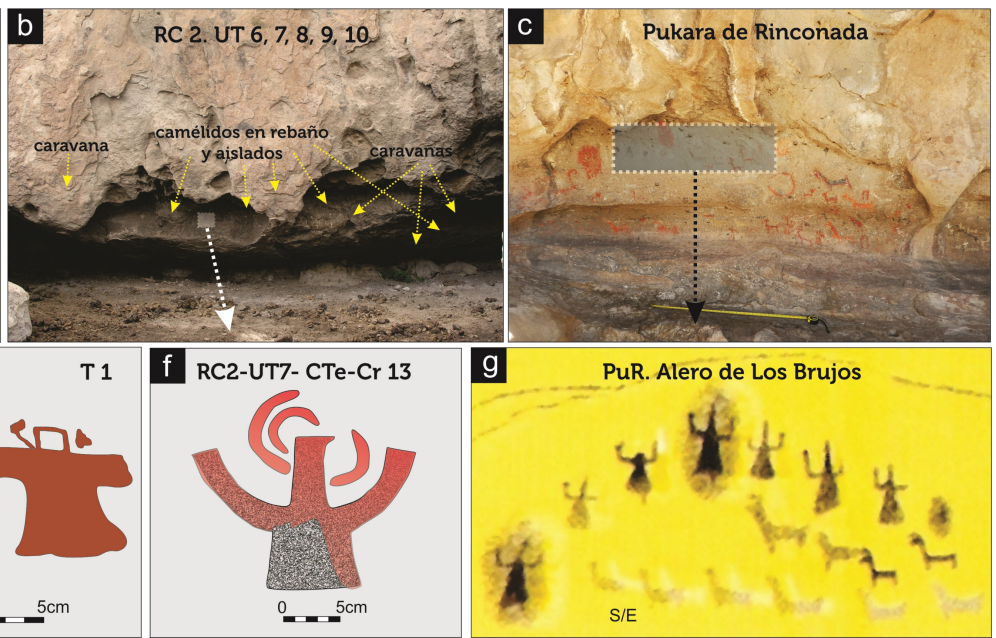

PuR. Alero de Los Brujos



Figura 13. (a) Antropomorfo del patrón H5 y su relación con camélidos en rebaño en T1. (b) y (c) Antropomorfo con brazos elevados articulando temas pastoril y caravanero en RC2 y en PuR, respectivamente. (d) Camélidos agrupados en columnas (rebaño) en T1. (e) Calco digital de antropomorfos $\mathrm{H} 5$ en T1. (f) Calco digital de antropomorfo con brazos elevados CTe-Cr13 de RC2. (g) Figuras humanas de brazos alzados en PuR (Ruiz y Chorolque 2007:47, figura 3).

(a) Anthropomorph pattern H5 and its relationship to camelids in herds in T1. (b) and (c) Anthropomorph with raised arms articulating pastoral and caravan themes in RC2 and in PuR, respectively. (d) Camelids grouped in columns (herd) in T1. (e) Digital replica of H5 anthropomorphs in T1. (f) Digital replica of anthropomorph with raised arms CTe-Cr13 of RC2. (g) Human figures with raised arms in PuR (Ruiz and Chorolque 2007:47, figure 3).

vinculado a ambos temas, y se registra además en la base residencial de $\mathrm{T} 1$ portando armas y asociado al tema pastoril.

En la puna meridional, este patrón H5 se ubica en general, en un espacio plástico diferente de aquel donde se registran las manifestaciones de caravanas, o en todo caso, si están compartiendo la misma UT, la relación existente es de superposición (o imposición) del antropomorfo " $T$ " sobre la caravana (o incluso sobre otros temas previos), evidenciando no solo su diacronía sino también la pertenencia a contextos de significación diferentes (Aschero 2000; Martel 2010). Sin embargo, esta situación es totalmente contrapuesta a la registrada en los sitios referidos de nuestra área (Figuras 3d, 12d, 13a, d y e).
Algunos autores proponen separar el análisis de los antropomorfos "T" y las escenas de enfrentamiento de figuras humanas con armas, de aquellas manifestaciones asociadas a temas caravaneros y pastoriles, por considerar que pertenecen a contextos de significación diferentes (Martel 2011). Sin embargo, las evidencias observadas en el sur de Pozuelos nos llevan a plantear no solo un fuerte vínculo entre los repertorios temáticos pastoril y caravanero, y su articulación con la recurrente presencia de la figura humana del patrón $\mathrm{H} 5$, sino también de todos ellos en relación a un entorno de conflictividad social.

Aschero (1998 [1996]) menciona que la reducción de los rangos de interacción caravanera y la presencia de conflictos interétnicos en el Período de Desarrollos 
Regionales, se refleja en el aumento de la estandarización de ciertos diseños y temas en el arte rupestre. En este sentido, no planteamos aquí un clima de beligerancia que haya condicionado totalmente la performatividad de los paisajes rupestres y de la vida cotidiana de los grupos de esta zona, sino que se propone discutir los paisajes (físicos y virtuales) de los pastores/caravaneros como agentes activos en un contexto de tensión y/o conflicto social entre grupos (Acuto 2007; Nielsen 2002, 2007, 2013), que pudo implicar el desarrollo de diferentes estrategias para la protección de las rutas de tráfico y de los asentamientos agro-pastoriles.

En este sentido, en todos los casos mencionados de nuestra área de estudio, el antropomorfo " $T$ " presenta una ubicación y una escala (sensu Alberti 2013) privilegiada en relación al resto de los motivos de cada sitio, en un vínculo que puede ser interpretado como una actitud protectora en torno a la recua o el rebaño, y de algún modo, hacia estos paisajes y/o rutas entramadas a las prácticas del caravaneo y pastoreo.

Por ello, reafirmamos nuestra crítica hacia la concepción de ver cuerpos pasivos representados en el arte rupestre, y ratificamos la posibilidad de abordar la performatividad y la sinergia de un sujeto/agente que emerge del espacio plástico.

En este contexto, pensamos que la sinergia (sensu Haken 1988) implicada en la configuración de la figura humana de la MECiR en general y del patrón H5 en particular, genera una corporalidad dominada por atributos culturales (adornos cefálicos, armas, vestimentas, género), de la cual emerge un sujeto contenido por fronteras caóticas y performativas, propiedades que compartiría con las identidades que pretende definir por medio de normas que operarían, en este caso, a través de un procedimiento regulado de repetición (sensu Butler 2007). Si pensamos estas corporalidades como una sinécdoque de lo social (Butler 2007), entonces los límites del cuerpo de la figura humana, definidos por formas específicas de saberpoder, corresponderían a los límites de lo socialmente hegemónico, que según lo observado estaría atravesado por la ritualidad.

Visto de este modo, la ritualidad inherente a las prácticas cotidianas, a través de la repetición y estandarización de ciertas corporalidades (por ejemplo, patrón H5), las relaciones que establece con otros motivos (ubicación y escala destacada), así como los contextos y paisajes en los que se emplaza (caravanero, pastoril, agro-pastoril, asentamiento-eje), garantiza la iteratividad y performatividad de esos límites socialmente hegemónicos, que permiten en la MECiR la emergencia de un sujeto colectivo muy pautado. Esta situación, que ubica aparentemente al ejecutor/ observador como un sujeto "sujetado" a las relaciones de saber-poder plasmadas en el espacio plástico, con un alto esfuerzo en estandarizar morfologías, contornos, paisajes, lazos sociales y la acción colectiva; puede justamente estar evidenciando la alta fragilidad de esas fronteras hegemónicas que intenta imponer.

\section{Consideraciones Finales}

Lo presentado en este trabajo desde el estudio del arte rupestre, paisajes y del contexto arqueológico, plantean la emergencia de "lugares" caravaneros y caravaneros/pastoriles, relacionados a rutas de ingreso/ egreso sur-occidental de la cuenca de Pozuelos. Los paisajes rupestres de AP1 y RC2, habrían tenido un rol diferencial no solo en el entramado de las prácticas caravaneras y pastoriles, sino también a la inherente ritualidad asociada a las mismas. Estos sitios se configuran como puntos de inflexión que hemos denominado paisajes coyunturales, que habrían sido específicamente seleccionados en relación a las rutas de tráfico caravanero como sitio de descanso de la tropa (realero o jarana) en AP1, y como un "lugar" que articula las ritualidades de la trashumancia pastoril y del tráfico caravanero en el caso de $\mathrm{RC} 2$, con una potencial base residencial en T1. Estos "lugares" se habrían articulado de diferentes modos al Pukara de Rinconada, que constituido como paisaje coyuntural de alta visualización y acceso restringido se habría desempeñado en este contexto, como asentamientoeje de la microrregión.

El estudio estilístico de las manifestaciones rupestres apoya lo expuesto anteriormente, pero además aporta ciertos aspectos a discutir. Por un lado, la confluencia en el PuR y en RC2, de las dos modalidades estilísticas definidas para la zona (MERH y MECiR) y de los temas caravanero y pastoril, mientras que en AP1 solo se presenta la MECiR, y solo el tema caravanero. Si bien en los tres sitios se registran varios eventos de ejecución de las manifestaciones rupestres, se destaca en RC2 la definición de 54 CTe y CTe-Cr, de los cuales 49 se vinculan a la MECiR con temas tanto caravaneros como pastoriles, que más allá de presentar superposiciones parciales y mayormente yuxtaposiciones que reutilizan elementos previos para la composición de nuevos motivos, en todos los casos no invalidan el contexto anterior, generando una suerte de actualización con una evidente continuidad conceptual a través del tiempo. Estas situaciones nos llevan a proponer el reúso de estos paisajes, que pudo ser mantenido y protegido por un grupo que perpetúa una lógica recurrente, sostenida por un mismo conocimiento técnico, composicional y conceptual en la manufactura del arte rupestre en particular, y en la reutilización espacial del sitio (repetidos eventos de quema en un mismo sector, área de molienda con profundos morteros, etc.). 
Las reiteradas escenas de recuas de llamas y su personaje guía asociadas a las figura humana del patrón H5 (antropomorfo " $T$ "), ejecutada de manera sincrónica y en posición destacada en el espacio plástico, tanto en AP1, $\mathrm{RC} 2, \mathrm{~T} 1$ como en PuR, abre una serie de implicancias cronológicas (sincronicidad de estos elementos) y en torno a posibles estrategias de "protección" de las rutas de tráfico caravanero y de la práctica del pastoreo para esta microrregión. Las escenas de caravanas, junto a la de rebaños, de camélidos en corrales, de hembras con sus crías, de camélidos enfrentados en clara actitud de agresión, los atributos de la figura humana y todas las relaciones establecidas entre ellos; nos lleva a pensar que el arte rupestre en el sur de Pozuelos no solo jugó un rol importante en ambas prácticas (caravanera y pastoril), sino que también materializa y performa (sensu Butler 2002, 2007) vínculos complejos entre ellas, justamente en paisajes coyunturales que articulan las lógicas y ritualidad de la movilidad trashumante de las prácticas pastoriles, con los modos de circulación del tráfico caravanero.

En la región circumpuneña, se remarca que la diversidad de estilos en sitios caravaneros indicaría diferentes orígenes de sus autores, distinguiendo de ese modo pastores locales de pastores en tránsito (Aschero 2000; Berenguer 2004; Martel 2010). En nuestro caso, de acuerdo a los resultados obtenidos, proponemos que en el sur de Pozuelos los pastores locales ocupados en el cuidado y la reproducción de los rebaños, serían los mismos que en ciertas estaciones del año se habrían dedicado también a las actividades caravaneras, generándose un manejo particular por parte de estos grupos locales, de ciertos "lugares" y repertorios temáticos vinculados a ambas prácticas. Esto no invalida la existencia de caravaneros no locales transitando las rutas de la microrregión, aunque hasta el momento esto no se ha evidenciado en el arte rupestre de los sitios estudiados por nosotros.

Esta continuidad estilística, conceptual y composicional en temas caravaneros y pastoriles y su articulación en un mismo paisaje, no es lo más frecuente en otros sitios de la circumpuna. Sin embargo, tal como hemos planteando en trabajos previos (Rodríguez Curletto 2014; Rodríguez Curletto y Angiorama 2016), la MECiR se caracteriza por una fuerte estandarización de conceptos y "modos de hacer", junto a una continuidad temática transpuesta en diferentes paisajes, que se extiende hacia la Quebrada de Humahuaca al sureste, y hacia el sur de la Puna (Barrancas, Doncellas, Coranzulí), llegando incluso hasta el norte de los Valles Calchaquíes.

Frente a esta situación, se abre la posibilidad de discutir la existencia de "territorios circulatorios" (sensu Tarrius 2000) vinculados tal vez a la reducción de los rangos de acción de las caravanas que ocurre en estos momentos, lo que implicaría una modalidad de interacción a corta distancia $(50-150 \mathrm{~km})$, articulada con circuitos de movilidad giratoria mayores interconectados (Aschero 2000) interregionalmente por medio de los "corredores internodales" a larga distancia de la "triple frontera" (Nielsen 2013).

Sin la intención de realizar extrapolaciones directas con nuestro caso de estudio, consideramos que la información aportada desde la etnoarqueología y la etnografía planteada como disparadora para ciertas preguntas sobre las características observadas en los sitios analizados, nos lleva a pensar en la existencia de una ritualidad performativa e iterativa en torno a las prácticas referidas, que si bien habrían tenido como fin principal renovar la relación de la comunidad con todos sus seres tutelares (por ejemplo, para la propiciación de viajes de tráfico y bienestar de sus rebaños), también pudo constituir una manera efectiva de performar relaciones de saber-poder, que por medio de esa ritualidad pudieron estar dispersas entre los diferentes sujetos-agentes del entramado social (sensu Foucault 1979, 2015).

De este modo, consideramos que estas prácticas de los pastores/caravaneros puede ser discutida en un contexto de tensión, conflicto social y/o beligerancia frecuente entre grupos referida para momentos de los Desarrollos Regionales (Acuto 2007; Nielsen 2002, 2007), para lo cual las estrategias de "protección" de los paisajes y prácticas vinculadas al tráfico y pastoreo habrían resultado esenciales, siendo la ritualidad inherente a dichas prácticas y a la cotidianeidad en sí misma, un aspecto fundamental en el desarrollo, performatidad e iteratividad de dichas estrategias a través del tiempo y de los diferentes paisajes de este sector de la puna jujeña.

Consideramos que el análisis y la articulación de los sitios presentados en este artículo constituyen tan solo un punto de partida para el estudio de una gran diversidad de aspectos relacionados con las prácticas pastoriles y caravaneras en el sur de Pozuelos. Esperamos que el enfoque aquí propuesto para abordar la complejidad en la emergencia de estos "lugares" brinde una base significativa para comprender y discutir otros paisajes rupestres de la microrregión y de regiones vecinas.

Agradecimientos: Agradecemos principalmente a cada uno de los habitantes del sur de Pozuelos por permitirnos trabajar en su territorio por más de una década, y a todos los miembros del equipo que participaron en las tareas de campo realizadas en el área de estudio. Las investigaciones fueron financiadas mediante subsidios PICT (FONCyT), PIP (CONICET) y PIUNT (Universidad Nacional de Tucumán). Agradecemos también los valiosos comentarios de los revisores anónimos. 


\section{Referencias Citadas}

Acuto, F. 2007. Fragmentación versus integración comunal: Repensando el Periodo Tardío del Noroeste Argentino. Estudios Atacameños 34: 71-95.

Albeck, M. y M. Ruiz. 2003. El tardío en la puna de Jujuy: poblados, etnias y territorios. Cuadernos FHyCS-UNJu, 20: 199-221.

Alberti, B. 2013. Archaeology and ontologies of scale: The case of miniaturization in First-Millennium Northwest Argentina. En Archaeology After Interpretation: Returning Materials To Archaeological Theory, editado por B. Alberti, A. Jones y J. Pollard, pp. 43-58. Left Coast Press, California.

Alfaro de Lanzone, L. 1969. Exploraciones arqueológicas en la Puna de Jujuy. Antiquitas 8:7-13.

Alfaro de Lanzone, L. y J. Suetta. 1970. Nuevos aportes para el estudio del asentamiento humano de la Puna de Jujuy. Revisión del Pucará de Rinconada. Antiquitas 10:1-10.

Alfaro, L. 1978. Arte rupestre en la cuenca del Río Doncellas (Provincia de Jujuy, República Argentina). Relaciones de la Sociedad Argentina de Antropología VII:123-146.

Aschero, C. 1998 [1996]. Arte y arqueología. Una visión desde la puna Argentina. Chungara Revista de Antropología Chilena $28(1-2): 175-197$.

Aschero, C. 2000. Figuras humanas, camélidos y espacio en la interacción circumpuneña. En Arte en las Rocas: Arte Rupestre, Menhires y Piedras de Colores en Argentina, editado por M. Podestá y M. de Hoyos, pp. 15-44. Sociedad Argentina de Antropología, Buenos Aires.

Aschero, C. 2006. De cazadores y pastores. El arte rupestre de la modalidad Río Punilla en Antofagasta de la Sierra y la cuestión de la complejidad en la Puna meridional Argentina. En Tramas en la Piedra. Producción y Usos del Arte Rupestre, editado por D. Fiore y M. Podestá, pp. 103-140. Sociedad Argentina de Antropología, Buenos Aires.

Barad, K. 2008. Living in a Posthumanist Material World: Lessons from Schrödinger's Cat. En: Bits of Life: Feminism at the Intersections of Media, Bioscience, and Technolog, editado por A. Smelik y N. Lykke, pp. 165-176. University of Washington press, Seattle.

Berenguer, J. 2004. Caravanas, Interacción y Cambio en el Desierto de Atacama. Sirawi Ediciones, Santiago.

Boman, E. 1908. Antiquités de la Région Andine de la Repúblique Argentine et du Désert d'Atacama. Imprimiere Nationale, París.

Braudel, F. 1984. Historia y las Ciencias Sociales. Traducido por J. Gómez Mendoza. Alianza, Madrid.

Briones, L., L. Núñez y V. Standen 2005. Geoglifos y tráfico prehispánico de caravanas de llamas en el desierto de Atacama (Norte de Chile). Chungara Revista de Antropología Chilena 37 (2):195-223.

Bugallo, L. 2010. La estética de la crianza. Los santos protectores del ganado en la Puna de Jujuy. En Arte Indígena: Categorías, Prácticas, Objetos, editado por M. Bovisio y M. Penhos, pp. 85102. Encuentro Grupo Editor, Córdoba.

Butler, J. 2002. Cuerpos que Importan. Sobre los Límites Materiales y Discursivos del Sexo. Paidós, Barcelona.

Butler, J. 2007. El Género en Disputa. El Feminismo y la Subversión de la Identidad. Paidós, Barcelona.
Coira, B., Caffe, P., Ramírez, A., Chayle, W., Díaz, A., Rosas, S., Pérez, A., Pérez, B., Orozco, O. y M. Martínez 2004. Hoja Geológica 2366-I/2166-III, Mina Pirquitas. Provincia de Jujuy. Instituto de Geología y Recursos Minerales, SeGeMAr, Boletín 269. Buenos Aires.

Criado Boado, F. 1999. Del terreno al espacio, planteamientos y perspectivas para la arqueología del paisaje. Cadernos de Arqueoloxía e Patrimonio 6:1-82.

Dransart, P. 2002. Earth, Water, Fleece, and Fabric: an Ethnography and Archaeology of Andean Camelid Herding. Routledge, London.

Dransart, P. 2011. Social principles of Andean camelid pastoralism and archaeological interpretations. En Ethnozooarchaeology: the Present Past of Human-Animal Relationships, editado por U. Albarella y A. Trentacoste, pp. 123-130. Oxbow Books, Oxford.

Fernandez Distel, A. 2007. Arqueología e Historia de un Valle Puneño: Barrancas (Jujuy, Argentina). 2a Edición. Editorial Dunken, Buenos Aires.

Flores Ochoa, J. 1974. Enqa, Enqaychu illa y Khuya Rumi: aspectos mágico-religiosos entre pastores. Journal de la Société des Américanistes 63:245-262.

Flores Ochoa, J. 1983. El ecosistema del pastoreo andino en las tierras altas de los Andes Centrales. En Sobrevivencia Campesina en Ecosistemas de Altura Vol. II., pp. 3-66. CEPAL y PNUMA, Santiago.

Foucault, M. 1979. Microfísica del Poder. Traducido por J. Varela y F. Alvarez-Uría. Ediciones de La Piqueta, Madrid.

Foucault, M. 2015. Vigilar y Castigar. Nacimiento de la Prisión. Siglo veintiuno, Buenos Aires.

Gabelmann, O. 2015. Caminando con llamas. Caravanas actuales y analogías para el tráfico e intercambio prehispánico en Bolivia. Estudios Sociales del NOA 15:33-58.

Galaty, J. y D. Johnson (eds.) 1990. The World of Pastoralism: Herding Systems in Comparative Perspective. The Guilford Press, New York.

Gell-Mann, M. 1995. El Quark y El Jaguar. Aventuras en lo Simple y lo Complejo. Tusquets Editores S.A., Barcelona.

Haken, H. 1988. Information and Self-organization. A Macroscopic Approach to Complex Systems. Springer, Berlin.

Harris, E. 1991. Principios de Estratigrafía Arqueológica. Traducido por I. García Trócoli. Crítica, Barcelona.

Hogg, A. G., Q. Hua, P. G. Blackwell, C. E. Buck, T. P. Guilderson, T. J. Heaton, M. Niu, J. G. Palmer, P. J. Reimer, R. W. Reimer, C. S. M. Turney y S. R. H. Zimmerman. 2013. SHCal13 Southern Hemisphere Calibration, 0-50,000 Years cal BP. Radiocarbon 55 (4):1889-1903.

Ingold, T. 2000. The Perception of the Environment. Essays on livelihood, Dwelling and Skill. Routledge, London.

Latcham, R. 1922. Los Animales Domésticos en la América Precolombina. Publicaciones del Museo de Etnología y Antropología, Santiago.

Lauricella, M. 2016. Marcas en el Camino. Arte Rupestre y Tráfico Prehispánico Tardío en el Sur de la Cuenca de Pozuelos (Puna de Jujuy, Argentina). Tesis para optar al grado licenciado 
en Arqueología. Facultad de Ciencias Naturales e Instituto Miguel Lillo, Universidad Nacional de Tucumán, San Miguel de Tucumán.

Lecoq, P. 1987. Caravanes de lamas, sel et échanges dans une communauté de Potosí, en Bolivie. Bulletin de l'Institut Français d'Etudes Andines XVI (3-4):1-38.

Lecoq P. y S. Fidel. 2003. Prendas simbólicas de camélidos y ritos agropastorales en el sur de Bolivia. Textos Antropológicos 14 (1):7-54.

López Campeny, S. y A. Martel. 2014. La vestimenta del poder. Comparando los registros textil y rupestre en el Noroeste de Argentina (siglos XIII a XV). Relaciones de la Sociedad Argentina de Antropología XXXIX (1):21-55.

Martel, A. 2010. Arte Rupestre de Pastores y Caravaneros. Estudio Contextual de las Representaciones Rupestres durante el Período Agroalfarero Tardio (900-1480 DC) en el Noroeste Argentino. Tesis para optar al grado de Doctor. Facultad de Filosofía y Letras, Universidad Nacional de Buenos Aires, Buenos Aires.

Martel, A. 2011. El espacio ritual pastoril y caravanero. Una aproximación desde el arte rupestre de Valle Encantado (Salta, Argentina). En En Ruta: Arqueología, Historia y Etnografía del Tráfico Surandino, editado por L. Núñez y A. Nielsen, pp. 111-150. Encuentro Grupo Editor, Córdoba.

Martel, A. y C. Aschero 2007. Pastores en acción: imposición iconográfica vs. autonomía temática. En Producción y Circulación Prehispánica de Bienes en el Sur Andino, compilado por A. Nielsen, C. Rivolta, V. Seldes, M. Vazquez y P. Mercolli, pp. 329349. Editorial Brujas, Córdoba.

Martel, A., S-Rodríguez Curletto y E. Del Bel 2012. Arte rupestre y espacios de memoria: las representaciones del sitio Confluencia (Antofagasta de la Sierra, Catamarca, Argentina). Revista Chilena de Antropología 25:121-162.

Medinaceli, X. 2005. Los pastores andinos: una propuesta de lectura de su historia. Ensayo bibliográfico de etnografía e historia. Bulletin de l'Institut Français d'études Andines 34 (3):463-474.

Nielsen, A. 1997. El tráfico caravanero visto desde la Jara. Estudios Atacameños 14:339-371.

Nielsen, A. 1997/1998. Tráfico de caravanas en el sur de Bolivia: observaciones etnográficas e implicancias arqueológicas. Relaciones de la Sociedad Argentina de Antropología XXII/ XXIII:139-178

Nielsen, A. 2002. Asentamientos, conflicto y cambio social en el altiplano de Lípez (Potosí). Revista Española de Antropología Americana 32:179-205.

Nielsen, A. 2003. Por las rutas del Zenta: evidencias directas del tráfico prehispánico entre Humahuaca y las Yungas. En La mitad Verde del Mundo Andino. Investigaciones Arqueológicas en la Vertiente Oriental de los Andes y las Tierras Bajas de Bolivia y Argentina, editado por G. Ortiz y B. Ventura, pp. 261-284. EdiUnju, Jujuy.

Nielsen, A. 2006. Estudios internodales e interacción interregional en los Andes circumpuneños: teoría, método y ejemplos de aplicación. En Esferas de Interacción Prehistóricas y Fronteras Nacionales Modernas: los Andes Sur Centrales, editado por H. Lechtman, pp. 29- 69. IEP-IAR, Lima.
Nielsen, A. 2007. Armas significantes: tramas culturales, guerra y cambio social en el Sur Andino Prehispánico. Boletín del Museo Chileno de Arte Precolombino 12 (1):9-41.

Nielsen, A. 2013. Circulating objects and the constitution of South Andean society (500 BC-AD 1550). En Merchants, Trade, and Exchange in the Pre-Columbian World, editado por K. Hirth y J. Pillsbury, pp. 389-418. Dumbarton Oaks, Washington D.C.

Nielsen, A. 2017. Las rutas de caravanas en los Andes como paisajes culturales. En Nuevas Tendencias en el Estudio de los Caminos, editado por S. Chacaltana, E. Arkush y G. Marcone, pp. 282-305.Ministerio de Cultura Proyecto Qhapaq Nan-Sede Nacional, Lima.

Nielsen, A., Vázquez, M., Mercolli, P. y V. Seldes 2001. Las Pictografías de Kollpayoc (Departamento Humahuaca, Jujuy, Argentina) En Arte Rupestre y Región. Arte Rupestre y Menhires en el Sur de Bolivia, Norte de Argentina y Norte de Chile, editado por A. Fernández, pp. 91-108. Anuario del Centro de Estudios Indígenas y Coloniales, UNJu, San Salvador de Jujuy.

Olsen, B. 2012. Symmetrical Archaeology. En Archaeological Theory Today, editado por I. Hodder, pp. 208-228. Polity, Cambridge.

Pimentel, G. 2009. Las Huacas del Tráfico. Arquitectura ceremonial en rutas prehispánicas del desierto de Atacama. Boletín del Museo Chileno de Arte Precolombino 14 (2):9-38.

Prezzi C. y F. Lince Klinger 2010. Nuevas evidencias geofísicas de la existencia de una caldera cubierta en laguna Pozuelos: puna norte. Revista de la Asociación Geológica Argentina 66 (1-2):282-295.

Rodríguez Curletto, S. 2014. Paisajes y Estilos del Arte Rupestre en la Cuenca Sur de Pozuelos. Tesis para optar al grado Licenciada en Arqueología. Facultad de Ciencias Naturales e Instituto Miguel Lillo, Universidad Nacional de Tucumán, San Miguel de Tucumán.

Rodríguez Curletto, S. y C. Angiorama 2016. El arte rupestre del sur de la cuenca de Pozuelos (900-1535 DC). Boletín del Museo Chileno de Arte Precolombino 21 (2):25-46.

Ruiz, M. y D. Chorolque 2007. Arte Rupestre del Pukara de Rinconada: una Larga Historia Visual. Universidad Nacional de Jujuy, San Salvador de Jujuy.

Súmar, J. 1991. Fisiología de la reproducción del macho y manejo reproductivo. En Avances y Perspectivas del Conocimiento de los Camélidos Sudamericanos, editado por S. Fernández-Baca, pp. 111-148. FAO, Santiago.

Tarragó, M. 2000. Chacras y Pukaras: Desarrollos Sociales Tardíos. En Nueva Historia Argentina Tomo I. Editado por M. Tarragó, pp. 257-300. Sudamericana, Buenos Aires.

Tarrius, A. 2000. Leer, describir, interpretar las circulaciones migratorias: conveniencia de la noción de territorio circulatorio. Los nuevos hábitos de la identidad. Relaciones. Estudios de Historia y Sociedad XXI (83):39-66.

Tilley, C. 2004. The Materiality of Stone: Explorations in Landscape Phenomenology. Berg, Oxford.

van Kessel, J. y A. Llanque Chana 2004. Rituales pastoriles de la puna el Kuti, o gran limpieza del ganado y 11 Jila Jikxata, o fiesta del empadre. Cuadernos de Investigación en Cultura y Tecnología Andina 7:5-73. 


\section{Notas}

${ }^{1}$ Si bien sabemos que son los pastores los que se dedican al caravaneo, también sabemos que no todos los pastores son caravaneros. De este modo, cuando hablamos de actividades pastoriles, nos referimos básicamente a las tareas de cuidado del rebaño llevadas a cabo por los pastores, y cuando nos referimos a las actividades caravaneras y al "caravanero" en particular, consideramos que se trata necesariamente de un "pastor" que en determinadas temporadas del año se dedica al caravaneo.

${ }^{2}$ CorelX6, DStretch (Jon Harman; http://www.dstretch.com), Adobe Photoshop, Pix4Dmapper, Agisoft Photoscan, entre otros.

${ }^{3}$ En la definición de los Conjuntos Técnicos se incluyen diferentes técnicas de grabados, mientras que en la definición de los Conjuntos Técnico-Cromáticos, además del tipo de grabado, se integran también las diferentes técnicas de pintura, considerando no solo el tipo de aplicación sino también las propiedades del color (tono, valor e intensidad) de las diferentes mezclas pigmentarias.

${ }^{4}$ Las Unidades Topográficas son definidas a partir de la orientación y topografía de la superficie rocosa, así como por la configuración distribucional de los motivos.

${ }^{5}$ La mayoría de los elementos plasmados en la orientación noreste-este (excepto UT8 y UT10) presentan diferentes grados de exposición al calor y al hollín, ya que en la base de estas UT se observan evidencias de varios eventos de quema, tanto contra el bloque rocoso como junto a las pircas adosadas al mismo que forman los corrales.

${ }^{6}$ El patrón H1 (cuerpo desnudo) de la figura humana no había sido registrado hasta el momento en el sector sur de Pozuelos en vinculación a la MECiR, aunque sí existían registros para el caso de la MERH. Sin embargo, en Río Candado 2 hemos registrado diferencias en las técnicas de ejecución, configuración diferencial del elemento, composición diferencial del motivo y tema en el que participa dicho elemento, lo que nos lleva a proponer que este patrón $\mathrm{H} 1$, con estos caracteres muy diferentes al registrado para la MERH, podría ser vinculado a la MECiR. En primera instancia puede parecer una excepcionalidad para nuestra área de estudio, sin embargo, al analizar este patrón (con los caracteres de este sitio) encontramos que puede ser vinculado a motivos similares más allá de nuestra área de estudio y asociados a la MECiR, particularmente hacia el sur (Barrancas) (Fernández Distel 2007).
${ }^{7}$ Fechado calibrado con el programa CALIB 7.0.4; Calibration data set: shcal13.14c (Hogg et al. 2013).

${ }^{8}$ Esta situación también se observa no solo en otros sitios de nuestra área de estudio (Casa Colorada 1, Pukara de Rinconada, Cienéga Rodeo 1), sino también en áreas aledañas como Kollpayoc (Nielsen 2001), Doncellas (Alfaro 1978) y en Barrancas (Fernández Distel 2007). Esto reafirma lo que venimos planteando en trabajos anteriores en relación a la Modalidad Estilística Ciénega Rodeo definida para el sur de Pozuelos, la cual presenta un alcance y una complejidad que se transpone desde esta microregión, hacia paisajes del sur de la puna de Jujuy (Casabindo, Doncellas, Coranzulí, Susques, Barrancas, y otros sectores de la cuenca de GuayatayocMiraflores), del norte de Salta, y de lugares localizados al sureste de Pozuelos hacia la Quebrada de Humahuaca (Tres Cruces, Inca Cueva, Kollpayoc) (Rodríguez Curletto 2014; Rodríguez Curletto y Angiorama 2016).

${ }_{9}^{9}$ La distancia que separa el Pukara de Rinconada de RC2 es de $17 \mathrm{~km}$ aproximadamente, distancia considerada dentro de los rangos estimados para una jornada de viaje con caravanas de llamas (Nielsen 2006).

${ }^{10}$ Señalkuy se le llama al rito de marcaje del ganado, que es cuando cada animal recibe su marca, siendo una de las ceremonias más importantes y complejas del culto ganadero andino, en el que se refuerza el vinculo del pastor/ la familia con sus animales. Es una ceremonia que busca retribuir a los animales que componen las tropas y revitalizar su poder vital o enqa (Flores Ochoa 1974; Lecoq y Fidel 2003).

${ }^{11}$ jila jikxata uywa ch'uwa significa "primera siembra y purificación del ganado", consiste justamente en un rito de purificación para garantizar la salud y bienestar del ganado, como así también la purificación del pastor, su casa, su familia, etc., al mismo tiempo que se da inicio a la temporada de apareamiento de los camélidos. Se realiza entre diciembre y enero que es cuando se inicia el empadre, el cual dura hasta el mes de abril (van Kessel y Llanque Chana 2004).

${ }^{12}$ Los ritos caravaneros se realizan en diferentes momentos y paisajes vinculados al viaje: en sitios relacionados al pernocte, en las jaranas de ocupación prolongada, en aquellos lugares que implican un cambio de etapa del viaje (abras, cumbres), etc. En estos ritos se busca la protección de la tropa, de los arrieros, los compadres y comadres y del propio acto de intercambio. 